\title{
Primary Metabolism in Fresh Fruits During Storage
}

\author{
Stefano Brizzolara ${ }^{1}$, George A. Manganaris ${ }^{2}$, Vasileios Fotopoulos ${ }^{2}$, \\ Christopher B. Watkins ${ }^{3}$ and Pietro Tonutti ${ }^{1 *}$
}

1 Institute of Life Sciences, Scuola Superiore Sant'Anna, Pisa, Italy, ${ }^{2}$ Department of Agricultural Sciences, Biotechnology \& Food Science, Cyprus University of Technology, Lemesos, Cyprus, ${ }^{3}$ School of Integrative Plant Science, College of Agriculture and Life Sciences, Cornell University, Ithaca, NY, United States

\section{OPEN ACCESS}

Edited by:

Robert Peter Walker,

University of Perugia, Italy

Reviewed by:

María Serrano,

Universidad Miguel Hernández de Elche, Spain Leon A. Terry,

Cranfield University,

United Kingdom

*Correspondence:

Pietro Tonutti

pietro.tonutti@sssup.it

Specialty section: This article was submitted to

Plant Metabolism and Chemodiversity,

a section of the journal

Frontiers in Plant Science

Received: 02 November 2019

Accepted: 21 January 2020

Published: 19 February 2020

Citation:

Brizzolara S, Manganaris GA,

Fotopoulos V, Watkins CB and

Tonutti P (2020) Primary Metabolism in

Fresh Fruits During Storage.

Front. Plant Sci. 11:80.

doi: 10.3389/fp/s.2020.00080
The extension of commercial life and the reduction of postharvest losses of perishable fruits is mainly based on storage at low temperatures alone or in combination with modified atmospheres (MAs) and controlled atmospheres (CAs), directed primarily at reducing their overall metabolism thus delaying ripening and senescence. Fruits react to postharvest conditions with desirable changes if appropriate protocols are applied, but otherwise can develop negative and unacceptable traits due to the onset of physiological disorders. Extended cold storage periods and/or inappropriate temperatures can result in development of chilling injuries (Cls). The etiology, incidence, and severity of such symptoms vary even within cultivars of the same species, indicating the genotype significance. Carbohydrates and amino acids have protective/regulating roles in $\mathrm{Cl}$ development. MA/CA storage protocols involve storage under hypoxic conditions and high carbon dioxide concentrations that can maximize quality over extended storage periods but are also affected by the cultivar, exposure time, and storage temperatures. Pyruvate metabolism is highly reactive to changes in oxygen concentration and is greatly affected by the shift from aerobic to anaerobic metabolism. Ethylene-induced changes in fruits can also have deleterious effects under cold storage and MA/CA conditions, affecting susceptibility to chilling and carbon dioxide injuries. The availability of the inhibitor of ethylene perception 1-methylcyclopropene (1-MCP) has not only resulted in development of a new technology but has also been used to increase understanding of the role of ethylene in ripening of both non-climacteric and climacteric fruits. Temperature, MAVCA, and 1-MCP alter fruit physiology and biochemistry, resulting in compositional changes in carbon- and nitrogen-related metabolisms and compounds. Successful application of these storage technologies to fruits must consider their effects on the metabolism of carbohydrates, organic acids, amino acids and lipids.

Keywords: low temperature, controlled atmospheres, modified atmospheres, hypoxia, ethylene, 1-methylcyclopropene, fruit composition, post-harvest 


\section{INTRODUCTION}

Harvested fruits are treated with a range of postharvest technologies to mantain quality by delaying ripening and senescence, preventing the incidence of physiological and pathological disorders, and avoiding water loss and physical damage. The main pillar of fruit storage is the use of refrigeration. Temperate fruit crops are commonly stored at temperatures close to freezing $\left(0-1^{\circ} \mathrm{C}\right)$, while those of tropical or subtropical origin must be kept at higher storage temperatures $\left(7-15^{\circ} \mathrm{C}\right)$ to avoid losses due to the development of chilling injury (CI) symptoms. These symptoms can be manifested as altered ripening behavior and external (peel) and/or internal (flesh) damages (browning, pitting, breakdown, discoloration), being more evident after subsequent removal from cold storage and maintenance at room temperarure. Appropriate storage temperatures can extend storage life by about 2-4 weeks for crops such as apricots, sweet cherries, and peaches, and up to several months for apples, pears, and kiwifruits.

Storage protocols that reduce oxygen and/or increase carbon dioxide concentrations in combination with low temperature are mainly used for fruits such as apples, pears, and kiwifruits. Similar conditions are also applied with modified atmosphere (MA) storage, usually applied as MA packaging (MAP) for minimally processed (fresh cut) products and to a lesser extent as whole fruits. For controlled atmosphere (CA) storage, the atmosphere composition is strictly monitored and adjusted in gas tight rooms by control systems, whereas in MA the changes in oxygen and carbon dioxide concentrations within the package are a function of factors such as the respiration rate of the produce as affected by cultivar, ripening stage, weight, and temperature in combination with packaging film characteristics. Optimum CA/MA storage regimes for different fruit types have been mainly developed empirically based on their quality after storage.

The main effects of low temperature and the CA/MA storage alone or in combination are associated with respiration, ethylene biosynthesis and its action, and other metabolic processes, thereby decreasing the rates of change that occur during postharvest ripening, including color (chlorophylls, carotenoids, and flavonoids), texture (softening as a result of cell wall disassembly and reduced cell turgor), and flavor (taste and aroma as a result of starch degradation, sugar-acid metabolism, and synthesis of aromatic volatiles). These effects can apply regardless of whether the fruit is non-climacteric or climacteric, but for the latter fruit types are important for reduction of ethylene production. Ethylene has a key physiological role during the ripening process, a genetically regulated stage of development of climacteric fruits that is highly complex and coordinated by hormonal metabolism. In addition to physical methods, a chemical antagonist of ethylene, 1-methylcyclopropene (1$\mathrm{MCP}$ ), is used on specific fruit types. 1-MCP effects vary depending on the species, cultivar, maturity and ripening stage, and factors such as 1-MCP concentration, treatment duration and temperature, and post-treatment storage conditions. It is commercially applied to several commercially important fleshy fruits, such as apples and pears
Storage technologies have profound effects on primary metabolism with marked consequences on the composition and the overall flavor of the commodity and, hence, the commercial life and the consumer acceptance. The objective of this review is to provide a perspective of these effects on the metabolism of carbohydrates, organic acids, amino acids, and lipids in fruits.

\section{LOW-TEMPERATURE STORAGE}

Low temperature is the main method used to extend storage and market life of fruits. By reducing general metabolism, cold storage protocols delay ripening and senescence processes through the control of the respiration rate. Low temperature is effective in decreasing the catalytic activities of different enzymes, including those involved in the different steps of respiration. The changes induced by temperature in a biological system are measured by using the Q10 temperature coefficient. This coefficient indicates the rate of reactions as a result of a temperature increase of $10^{\circ} \mathrm{C}$ (Atkin and Tjoelker, 2003). For most of harvested fruit crops, within a temperature range of 5$25^{\circ} \mathrm{C}$, Q10 values associated with respiration are, in general, between 2.0 and 3.0. This indicates that when lowering storage temperature from 20 to $10^{\circ} \mathrm{C}$ the respiration is decreased by a factor of 2-3, with positive consequences in terms of shelf/ commercial life of the produce. The optimum low-temperature and storage duration are highly variable based on the fruit type and are applied keeping in mind two principles: (1) low temperatures slow down general metabolism and reduce the rate of compositional changes; and (2) temperatures lower than a specific threshold and/or a prolonged cold storage induce physiological disorders. For the non-chilling sensitive fruit types, the storage temperatures are set just above their freezing point. Other types, e.g., tropical or sub-tropical fruits, must be stored at higher temperatures, typically between 7 and $15^{\circ} \mathrm{C}$. Factors such as cooling rates and precooling techniques also play a key role in determining the success of cold storage (Valero and Serrano, 2010). As a general effect, low-temperature storage upregulates stress-responsive genes, blocks signal transduction of ethylene-related processes, and affects both primary and secondary metabolism (Yun et al., 2012; Lin et al., 2018). Changes at the level of secondary metabolism during lowtemperature storage have been extensively studied, mostly focusing on how cell wall alterations affect abnormal ripening (Brummell et al., 2004). Despite the well-documented CIinduced activation of genes that are involved in different metabolic pathways (Gonzalez-Aguero et al., 2011), information about the effects of cold storage on fruit primary metabolism remains limited.

\section{Carbohydrate Metabolism}

Carbohydrates influence the sensitivity of plant tissues and organs, including fruits, to low temperature. Besides being an important fruit component markedly impacting the overall flavor, soluble carbohydrates may have several beneficial effects 
in protecting plants against stresses, including cold storage regime, and the relationship between CIs and carbohydrate metabolism was investigated in an array of fruit types. Special focus has been addressed to commercially important fruits, such as apples, pears, kiwifruits, and bananas that, at physiological maturity, are characterized by high starch contents that are converted to sugars during storage. An emerging research area is the impact of carbohydrate composition and contents on the sensitivity of fruits to low temperatures, although results are inconsistent (Zhao H. et al., 2019). Furthermore, over the recent years, a number of studies reported the effects of applications of chemicals on CI development in fruits in relation to sugar metabolism and/or changes in carbohydrate content. Excellent examples of sugar metabolism during cold storage of two distinct fruit types (peach, mandarin), which are characterized by abnormal ripening after cold storage, are available.

Carbohydrate metabolism has been extensively studied in cold-stored peaches with differential responses of individual sugars, mainly associated with CI symptoms, evident as browning. Enhanced chilling tolerance in peaches has been associated with higher sucrose contents, resulting from the balance between its degradation and biosynthesis, which may contribute to membrane stability (Wang et al., 2013). Brizzolara et al. (2018) found that "Red Haven" peaches had higher contents of sucrose and sugar alcohols such as sorbitol and maltitol after cold storage and reduced susceptibility to CI compared with "Flaminia" and "Regina di Londa" fruits. Induction of chilling tolerance of nectarines stored at near freezing temperatures $\left(-1.4^{\circ} \mathrm{C}\right)$ has been associated to reduced activities of sucrose metabolism-associated enzymes that resulted in higher sucrose contents (Zhao H. et al., 2019). Sound peaches were characterized by higher activities of hexokinase, fructokinase, and energy metabolism-associated enzymes and higher content of sucrose and lower contents of fructose and glucose were associated with reduced CI induced by glycine betaine treatment (Wang L. et al., 2019).

In citrus, the carbohydrate changes occurring in the flavedo along with fruit maturation do not appear to be related to the chilling tolerance in cold stored "Fortune" mandarins (Holland et al., 1999). Pre-storage heat conditioning (3 days at $37^{\circ} \mathrm{C}$ ) enhanced chilling tolerance of the fruits, favoring sucrose, but not hexose, accumulation. This effect was attributed to heatinduced increase in the activities of sucrose-synthesizing enzymes, such as SPS and SuSy (Holland et al., 2005). Heat treatment limited the decline in sucrose content of flavedo tissue during cold storage, evidenced by the substantially higher amounts of sugars in heat-conditioned compared with nonconditioned fruits (Holland et al., 2002). Heat conditioning led to loss of glucose, fructose, and starch in fruit kept subsequently at $2^{\circ} \mathrm{C}$, suggesting that only sucrose is actively involved in the heat-induced chilling tolerance of citrus fruits.

Collectively, the role of sugar synthesis during cold storage on the incidence of CI symptoms should be evaluated on a species basis and also based on the nature and symptomology of each chilling related disorder. Comparative studies can be convincing, but it is not always certain that the variation among cultivars is smaller than variations between chilling-tolerant and chillingsensitive cultivars; simple comparisons of two cultivar responses should be discouraged.

\section{Organic Acid Metabolism}

There is increasing evidence that organic acids act not only as intermediates in carbon metabolism but also as key components in response to environmental stress factors (Lopez-Bucio et al., 2000). In most fruits, the organic acid pool decreases during ripening, and low temperature storage limits the rate of titratable acidity (TA) loss: this is imputed to the reduced metabolism, in particular respiration. In different kiwifruit cultivars, Cha et al. (2019) reported significantly lower TA values in fruit kept at $18^{\circ}$ $\mathrm{C}$ compared to 10 and $5^{\circ} \mathrm{C}$ storage.

Considering the fate of specific organic acids during cold storage, a genotype-dependent behavior is present. Bustamante et al. (2016) showed that six different peach genotypes displayed a decrease in 2-oxoglutarate (2-OG) and succinate contents during refrigerated storage. Decreases of malic and quinic acid contents were observed in myrtle fruits stored at 2 and $10^{\circ} \mathrm{C}$ (Angioni et al., 2011; Mulas et al., 2013), indicating a possible shift of metabolic activity toward the biosynthesis of secondary metabolites such as anthocyanins. An increasing number of reports highlight the link between postharvest treatments performed prior to cold storage and organic acid metabolism. Zhou et al. (2019) demonstrated that UV-treated peaches stored at $1^{\circ} \mathrm{C}$ were characterized by a down-regulation of aconitase and NADP-malic enzyme activities and gene expression levels, but higher levels of citrate synthase and NAD-malate dehydrogenase, resulting in a reduced degradation of citric and malic acids. Interestingly, pre-cold storage hot air treatment $\left(40^{\circ} \mathrm{C}, 48 \mathrm{~h}\right)$ in ponkan orange promoted citric acid degradation, attributed to regulation by ATP citrate lyase (ACL) and $\gamma$-aminobutyric acid (GABA) pathways (Gao et al., 2018).

\section{Amino Acid Metabolism}

Amino acid metabolic responses of fruits to cold storage are species- and storage condition-specific. For example, Micro-Tom tomatoes stored at $4^{\circ} \mathrm{C}$ resulted in a rise in Glu, Gln, Asp, and Asn contents (Gonzalez et al., 2019). Cold storage also increased endogenous substrate proteolysis, azocaseinolytic activity, and free amino acid contents, but their specific roles have not been elucidated (Re et al., 2012). Similar approaches have been employed for other species such as kiwifruit, where cold storage resulted in increased Thr, Ile, and Val contents, but not of Gln and Asn (Salzano et al., 2019). In peaches, the beneficial effect of heat pre-conditioning to alleviate CI symptoms was linked with the modification of metabolites, including sugars, polyamines, and amino acid precursors of the phenylpropanoid pathway (Lauxmann et al., 2014). Bustamante et al. (2016) reported that cold storage of six peach cultivars at $0^{\circ} \mathrm{C}$ resulted in increased GABA, Asp, and Phe contents, and a genotypedependent tolerance of peach cultivars to CIs was associated with higher amino acid contents (Brizzolara et al., 2018). 


\section{Lipid Metabolism}

Fatty acids are essential cell membrane components, constituting a selectively permeable barrier which represents an accessible fluid medium for lipophilic molecules/complexes and a matrix for enzymes that catalyze different metabolic reactions. Stress conditions alter membrane lipids, especially their level of unsaturation, altering membrane functioning, leading to ion leakage and cellular decompartmentalization (Marangoni et al., 1996). However, information about lipid metabolism of fruit during refrigerated storage is limited.

In peaches, the genotype affects the relative amounts of plastidic glycerolipid and triacylglyceride forms, possibly indicating their use as a source of energy during fruit senescence (Bustamante et al., 2018). Posphatidylethanolamine, phosphatidylcholine (PC), and digalactosyldiacylglycerol (DGDG) contents are possible markers of cold tolerance, given the important role played by the membranes in the development of CI symptoms. Wang Y. et al. (2019) found increased DGDG contents in blueberries after 30 and 60 days of storage at $0^{\circ} \mathrm{C}$. Other lipids such as phosphatidic acid (PA) are accumulated in pineapple fruit during blackheart development at $10^{\circ} \mathrm{C}$ (Zhou et al., 2014). Accumulation of PA could be linked with previously observed increased activity of phospholipase D (PLD) in coldstored fruits, as PLD hydrolyzes structural phospholipids such as PC to PA and a free-head group such as soluble choline (Wang, 1999). Sheng et al. (2016) and Shi et al. (2018) also measured increased PLD enzyme activities and transcript levels in coldstored pears. Similarly, chilling injured "Honeycrisp" apples with soggy breakdown had elevated contents of glycerol and TAGs (Leisso et al., 2015).

\section{CA AND MA STORAGE}

An extensive amount of information is available regarding the responses of different fruit types to reduced oxygen and elevated carbon dioxide concentrations (Yahia, 2009; Gross et al., 2016; Thompson et al., 2018). At commercial level, CA storage is widely applied to extend storage potential of commercially important commodities such as apples, pears, and kiwifruits.

For apples, traditional CA storage regimes (oxygen concentrations above $1 \mathrm{kPa}$ ) is being replaced by use of ultralow oxygen (ULO) concentrations $(<1 \mathrm{kPa})$. Dynamic CA (DCA) allows use of much lower oxygen concentrations. Measurement of physiological/biochemical responses of fruit to low oxygen by chlorophyll fluorescence (Prange et al., 2005), ethanol production (Gasser et al., 2008) and the respiratory quotient (RQ) (Bessemans et al., 2016) is allowing storage closer to the anaerobic compensation point (ACP).

The effects of low-oxygen storage depend on the intensity and duration of the applied stress on fruit metabolism. The fruit type, cultivar, maturity and ripening stage, and pre-harvest conditions are also important factors affecting behavior of harvested fruits. Most of the fundamental information available concerning the primary metabolic changes in CA-stored fruits (mainly apples and, to a lesser extent, pears) derives from studies where both oxygen and carbon dioxide concentrations were altered.
Therefore, it is not always easy to discriminate between the effects of the two conditions, especially where synergistic or additive effects occur, e.g. the responses of specific components and reactions of the tricarboxylic acid-cycle, and the fermentation products (acetaldehyde, ethanol, and ethyl acetate) (Kanellis et al., 2009).

\section{Carbohydrate Metabolism}

A major effect of low oxygen concentrations in fruit responses is the switch from the aerobic to anaerobic metabolism to compensate for energy deficits. Severe oxygen deficiency reduces mitochondrial respiration resulting in limited ATP availability for energy-demanding processes. Fruit metabolism responds to this energy crisis by increasing substrate level ATP production through different processes, including the catabolism of soluble sugars and, in some species, of starch. For example apples, during the advanced developmental stages, accumulate starch that decreases during CA storage (Gorin et al., 1978). In rice seed hypoxia induces the up-regulation of $\beta$-amylase genes that are activated to satisfy the increased carbon demand by glycolysis (Planchet et al., 2017). $\beta$-Amylase is also induced by low oxygen in apples (Cukrov et al., 2016). Futile cycles involving sucrose/hexose interconversion are considered the main mechanisms producing the specific sugar types in fruit tissue in normoxia (Nguyen-Quoc and Foyer, 2001). Low oxygen concentrations affect sugar-metabolism-related enzyme activities and gene expression in fruits. However, contents and the fate of simple sugars (glucose, fructose) and sucrose in fruit under CA conditions are still not yet fully clarified. Different responses may be a function of different oxygen and carbon dioxide concentrations, temperatures, and storage durations as well as effect of genotype. The decline of sucrose contents after harvest is slower in CAs than in air for apples (Zhu et al., 2013) and peaches (Lara et al., 2011), and associated with lower invertase but higher SuSy activities (Zeng et al., 1999; Geigenberger, 2003). SuSy gene expression is highly induced in apples under hypoxic conditions, as also observed in the model species Arabidopsis (Mustroph et al., 2010), representing a key responsive gene to hypoxia in fruit tissues (Cukrov et al., 2016). SuSy induction has been related to the activation of alternative pathways that use inorganic pyrophosphate (PPi) instead of ATP phosphorylation reactions to compensate for severe ATP deficiency. In apples kept from 0.4 to $3.0 \mathrm{kPa}$ oxygen, fructose and glucose do not show significant changes within 30-60 days of storage, probably due to similar rates of consumption and synthesis (Bekele et al., 2016; Cukrov et al., 2016). To meet the energy demand under low oxygen concentrations, an increase in carbohydrate flux through glycolysis occurs with the conversion of glucose-6-phosphate to pyruvate (Pasteur effect). The oxygen concentrations activating the responses leading to the Pasteur effect vary depending on fruit type and the ACP. The conversion of fructose-6-phosphate to fructose-1,6-biphosphate is catalyzed by phospho-fructo kinase (PFK) that is rapidly induced under hypoxia in apples. In "Granny Smith" apples, PFK is highly responsive to subtle changes in oxygen concentration (Cukrov et al., 2016), and, similarly to SuSy, uses PPi instead of ATP to 
save energy (Bailey-Serres et al., 2012). PFK most likely represents a key element for re-setting carbon metabolism under oxygen deficiency through an induction of the glycolytic pathway in rice (Mustroph et al., 2013). Both PFK and pyruvate kinase (PK) are highly and rapidly responsive to subtle changes of oxygen concentrations in apple tissues (Brizzolara et al., 2019). $\mathrm{NADP}^{+}$and $\mathrm{NAD}^{+}$must be regenerated to maintain the glycolytic flux and the concentration of pyruvate, which cannot be used in Krebs cycle in the absence of oxygen, must remain low (Bailey-Serres et al., 2012; António et al., 2016). To decrease its concentration and further produce ATP, pyruvate is redirected toward the fermentation pathways that produce lactate, acetaldehyde and ethanol with, at the same time, the maintenance of the redox balance in the cell by the formation of $\mathrm{NAD}^{+}$.

Ethanol production/accumulation occurs in apples stored under both static and DCA (Saquet and Streif, 2008; Cukrov et al., 2016; Brizzolara et al., 2017), and also in relation to the onset of low oxygen-related physiological disorders (Vandendriessche et al., 2013; Lumpkin et al., 2014). The metabolic responses including the activation of the fermentation pathway and the accumulation of related metabolites in apples stored under low oxygen/high carbon dioxide concentrations is highly variable depending on a number of factors, including the genotype, climatic conditions and agronomic practices, pre-treatments before storage, and CA protocols (Tonutti, 2015; Zanella and Sturz, 2015; Boeckx et al., 2019). "Granny Smith" and "Red Delicious" apples have different ACPs and accumulation patterns of ethanol, acetaldehyde, and lactate under static and DCA conditions; "Red Delicious" accumulates fermentative metabolites at higher oxygen concentrations $(0.9 \mathrm{kPa})$ than "Granny Smith," highlighting significant genotype differences (Brizzolara et al., 2017).

While accumulation of lactate is negligible during fermentative metabolism in CA-stored apples (Saquet and Streif, 2008), the transient increase of acetaldehyde and ethanol contents characterizes the early responses of apple fruits to oxygen concentrations below the specific ACP for a given cultivar. Interestingly, after an increase of fermentation metabolites, their concentration decreases after prolonged exposure to low oxygen stress (Cukrov et al., 2016; Brizzolara et al., 2017; Boeckx et al., 2019). The physiological mechanism responsible for this behavior remains to be elucidated.

The reduction of acetaldehyde to ethanol catalyzed by $\mathrm{ADH}$ is a key biochemical step in plant responses to hypoxic conditions. Specific $A D H$ family members can be identified as coreresponsive genes to hypoxia in apples. In fact, $A D H$ genes are extremely reactive to changes in oxygen concentrations showing fine-tuned regulated expression of different members belonging to this multigene family (Cukrov et al., 2016; Brizzolara et al., 2019). However, the regulatory mechanisms of fermentative metabolism in fruits in response to low oxygen concentrations are complex. Based on kinetic modeling of responses of apple slices to low oxygen concentrations, two mechanisms were suggested by Boeckx et al. (2019): (1) the molecular control of the transcript and protein levels of PDC, ADH, and LDH and (2) the metabolic control of these enzymes by changing cytosolic $\mathrm{pH}$ set-points, cofactors, and substrate levels. These authors suggest that the fermentative metabolism is highly dependent on factors that modulate reaction rates, with both molecular and metabolic control systems being activated when the overall metabolic rate is fast.

Mannose and melibiose contents increased under low oxygen conditions. (Hatoum et al., 2014; Brizzolara et al., 2017). Together with other sugar alcohols, melibiose plays an osmoprotection role and it is involved in stress responses, accumulating in stress-tolerant species, and is a stress markers in plants (Hill et al., 2013). Increased sugar alcohols have been observed in different fruits kept at low oxygen concentrations (Pedreschi et al., 2009). Given their antioxidant potential, such compounds may act directly as protectant molecules, or in complementing carbon storage reserves under sugar shortages (Moing, 2000).

\section{Organic Acid Metabolism}

A general decrease of organic acid concentrations in plant tissues may be a survival strategy aimed at reducing the flux toward nitrogen metabolism to keep on producing substrates for the glycolysis (Geigenberger, 2003; Galili, 2011; Ampofo-Asiama et al., 2014). Organic acids are key elements of the adaptive response of fruit tissue to low oxygen stress, although the overall pattern of organic acids in fruits stored under low oxygen and high carbon dioxide concentrations has still to be defined in detail. Succinate, a key metabolite in hypoxic responses, increases under low oxygen stresses in model systems (Bailey-Serres et al., 2012). Succinate also accumulates in apples and pears under high carbon dioxide concentrations (Vandendriessche et al., 2013; Bang et al., 2019), and this is associated with the inhibition of succinic dehydrogenase activity (Gonzalez-Meler et al., 1996). Accumulation of succinate has been correlated with the development of carbon dioxide-related physiological disorders (Pedreschi et al., 2008), although succinate can accumulate in the presence of the antioxidant diphenyamine, which prevents carbon dioxide injury (Fernandez-Trujillo et al., 1999). The effects of low oxygen concentrations in fruit tissues seem to be slightly different from those detected in rice and Arabidopsis. Lower levels of succinate have been detected in "Granny Smith" fruits kept at $0.4 \mathrm{kPa}$ compared with those maintained at $0.8 \mathrm{kPa}$ oxygen (Brizzolara et al., 2019), while "Red Delicious" fruit had higher succinate contents under static conditions at $0.9 \mathrm{kPa}$ oxygen compared with $0.2-0.55 \mathrm{kPa}$ oxygen (Brizzolara et al., 2017). One hypothesis is that GABA is catabolized to succinic semialdehyde (SSA) and then to succinate, with the latter reaction being catalyzed by SSA dehydrogenase (SSADH) in air-stored fruit. Under hypoxia, SSADH activity is likely reduced by increases in reducing potential and adenylate energy charge, thus resulting in the increase of GABA and the decrease of succinate. The effects of low oxygen/high carbon dioxide concentrations in fruits in relation to succinate metabolism need to be further elucidated.

The fate of malate is also affected by low oxygen concentrations. In general, the lower the oxygen concentration 
during storage, the greater the malic acid contents are maintained (Hatoum et al., 2016). Hypoxia induces aerobic respiration processes and affects specific TCA enzymes (Ampofo-Asiama et al., 2014). Normally, a decrease in malate content occurs in pome fruits after prolonged storage under hypoxia, which can be attributed to advanced ripening, and higher malate contents in the inner cortex compared with the outer cortex is probably the result of the lower respiration rate of this tissue due to reduced oxygen availability (Hatoum et al., 2016).

Fumarate contents increase under CA conditions, especially with higher carbon dioxide concentrations (Vandendriessche et al., 2013; Hatoum et al., 2016), perhaps as a result of downregulation of fumarase, which catalyzes the hydration of fumarate to malate (Pedreschi et al., 2007). CA storage also may contribute to higher fumarate contents by promoting the conversion of oxaloacetate from phosphoenolpyruvate through the reversal of TCA reactions (Pedreschi et al., 2009).

In contrast, citrate contents in fruits are stable during air storage, but decline in CAs (Flaherty et al., 2018a). Citrate accumulation could result from the efflux of the vacuolar reserves, where most citrate is stored (Etienne et al., 2013). Citrate contents are also linked to glutamate fate since this latter is formed from 2-oxoglutarate (2-OG) and ammonia through the activity of cytosolic glutamate dehydrogenase, while 2-OG is produced from stored citrate (Sweetlove et al., 2010).

\section{Amino Acid Metabolism}

In addition to the activation of the fermentative pathways to sustain glycolysis in the absence of mitochondrial respiration, nitrogen metabolism is profoundly affected by oxygen deprivation.

Amino acids linked to the TCA cycle are an integral component of respiratory metabolism and changes in their contents represent one of the main responses of plants to oxygen stress. Tolerant plants (e.g. rice) generally accumulate amino acids such as Ala, Ser, and Gly when subjected to low oxygen stress (Shingaki-Wells et al., 2011). The accumulation of $\mathrm{Ala}$ and GABA appears to be common responses of plants to hypoxia (Narsai et al., 2011). It has been hypothesized that Ala formation is important for removal of accumulated pyruvate under oxygen deficiency, thus indirectly contributing to $\mathrm{pH}$ homeostasis by competing with lactate dehydrogenase (Mustroph et al., 2014).

The contents of many different amino acids, such as Ala, Asp, GABA, Pro, Ser, and Thr in apples are modulated by oxygen concentrations during CA storage, with pyruvate-derived compounds and the expression of related metabolic genes affected differently by low oxygen concentrations (Cukrov et al., 2016).

Ala, which has been found to be a main hypoxia-related metabolite accumulating in several plant species (Bailey-Serres et al., 2012; Diab and Limami, 2016) including apples (Vandendriessche et al., 2013; Hatoum et al., 2014; Cukrov et al., 2016; Brizzolara et al., 2017), derives from pyruvate transamination via alanine aminotransferase (AlaAT) activity coupled to two different possible reactions: the production of 2OG from glutamate or the generation of SSA from GABA (Hyun et al., 2013). The GABA shunt is less efficient at generating 2-OG and, thus, it is possible that alanine is derived from Glu under low oxygen concentrations, and that plant cells use it as storage form of pyruvate. Hatoum et al. (2016) reported increases of alanine contents in "Braeburn" apples after 8 months of CA storage. In "Granny Smith" apples Ala content increases very rapidly after low oxygen stress is imposed but, differently from ethanol, a less marked effect of oxygen concentration is present (Cukrov et al., 2016). AlaAT gene expression is highly induced by hypoxic stress in apple cortex and a rapid re-adjustment of transcription occurs in relation to oxygen concentrations applied under DCA conditions (Brizzolara et al., 2019).

GABA appears to play a key role in energy metabolism and defence against different abiotic stresses in fruits (Shang et al., 2011; Yang et al., 2011; Wang et al., 2016). GABA represents a key compound in the interface between $\mathrm{C}$ and $\mathrm{N}$ metabolism under energetically demanding stresses possessing a pivotal role in stress responses, due to its double role of acting directly as protectant compound and functioning as signalling molecule used by plant tissue to tune stress responses (Michaeli and Fromm, 2015; Takayama and Ezura, 2015; Diab and Limami, 2016). GABA synthesis is enhanced when the cytosolic pH decreases (Hyun et al., 2013), hence its production could also be related to the fate of the organic acids in the cell, possibly being a tissue- or treatment-specific event also uncoupled from the response to low oxygen concentrations itself. The accumulation of GABA is highly dependent on the oxygen concentrations (Cukrov et al., 2016) and enhanced concentration of GABA are considered as a marker of hypoxia in apples and pears (Pedreschi et al., 2009; Cukrov et al., 2016). In addition, GABA catabolism is highly reactive and sensitive to oxygen and carbon dioxide changes. Decreases of GABA content have been detected in apple cortex tissues within $24 \mathrm{~h}$ of oxygen shift from 0.4 to $0.8 \mathrm{kPa}$ (Brizzolara et al., 2019) and two apple GABA transaminase (GABA-T) genes are rapidly up-regulated in apples moved from CA to normoxic conditions (Trobacher et al., 2013). GABA contents have been also reported to increase in strawberries and tomatoes during postharvest treatment with $20 \mathrm{kPa} \mathrm{CO} 2$ (Deewatthanawong et al., 2010a; Deewatthanawong et al., 2010b).

Overall, Ala and GABA production are important adaptive process allowing carbon and nitrogen storage, as well as acting as osmoprotectants under stress conditions, and balancing a rapid decrease in carbohydrates. Ala production under hypoxic stress represents an adaptive carbon allocation strategy that maintains the glycolytic flux, limits pyruvate accumulation and, at the same time, maintains carbon resources in the cell (Rocha et al., 2010). In fact, the fermentative pathway and ethanol production result in NAD+ regenration thereby allowing glycolysis to proceed to sustain ATP production, but the pathway drains carbon for the production of metabolically useless dead-end products (Limami, 2014). In addition, the interconversion of other amino acids normally takes place at cellular level acting as a tool for adapting 
cell metabolism/homeostasis to different environments. Therefore, hypoxia affects the fate also of other compounds belonging to this chemical class. Among them, Glu, Pro, as well as Ile, Thr, and Ser production/accumulation increase, while Asp and Asn contents showed a decrease in fruits stored under low oxygen concentrations (Lee et al., 2012; Hatoum et al., 2014; Bekele et al., 2016; Cukrov et al., 2016; Brikis et al., 2018). These results are mainly in agreement with the role of these amino acids as precursors for Ala and GABA production (Oliveira and Sodek, 2013).

\section{Lipid Metabolism}

Lipid metabolism in fruits under CA conditions is not well studied. Lipid biosynthesis is characterized by several pathways involving enzymes that require oxygen for their activity, such as the ones involved in the biogenesis of sterols and the desaturation of fatty acids (Harwood, 1988; Ohlrogge and Browse, 1995), and which may be affected by hypoxia. Indeed, lipid biosynthesis and desaturation have been since long time recognized to decrease in plants subjected to low oxygen concentrations (Brown and Beevers, 1987).

An early study postulated that phospholipids accumulated more slowly in apples stored in CA than in air (Bartley, 1986), while Brackmann et al. (1993) found lower peel fatty acid content in CA- than air-stored apples. CA storage affected the biosynthetic mechanisms of these compounds, especially linoleic acid. How different oxygen concentrations exert their effect on such pathways is still unclear. Production of unsaturated fatty acids, such as linoleic acid, requires oxygen and this partly explains their lower content under CA conditions. However, lipid biosynthesis could also be reduced because CA conditions inhibit respiration and general metabolism, thereby reducing the available energy equivalents, such as NADPH, that are needed for fatty acid synthesis (Ho et al., 2013). Delaying CA storage of apples results in higher contents of fatty acids, and polar lipids, including phospholipids after storage (Saquet et al., 2003). In addition to the energy issue, another possible cause of the observed decrease of lipids under low oxygen conditions involves ethylene production and action, which are lower after CA storage: in apples a pre-storage treatment with the inhibitor of ethylene biosynthesis, aminoethoxyvinylglycine, decreased ATP and fatty acid levels under storage in normoxia (HalderDoll and Bangerth, 1987).

Higher PCs and phosphatidylethanolamines (PEs) and lower arachidonic acid contents, the latter a product of PC and PE metabolism, have been observed in apple cortex one day after a partial re-oxygenation of the fruit when compared with apples stored constantly at low oxygen regimes (Brizzolara et al., 2019). This study reported that after oxygen re-supply the up-regulation of two genes encoding phospholipase A2 and the downregulation of two phospholipases ( $\mathrm{C} 2$ and $\mathrm{D}$ delta) occurred, indicating that phospholipid metabolism is highly reactive to slight changes in oxygen concentrations within the storage rooms. These results also pointed out that a transient burst of phospholipid metabolism could play an important role in the early responses of apple cortex cells subjected to oxygen re- supply, as well as in the generation of regulatory signals. Phosphoglycerides are main components of cell membranes, and mitochondria membranes are particularly rich in PC and PE (Harwood, 1987). Lipid metabolism in plants is altered under stress conditions: Xie et al. (2015) demonstrated that in hypoxic Arabidopsis, rosettes are characterized by increases in unsaturated glycerolipid species, PA, as well as oxidized membrane lipids, and decreases of phosphatidylglycerols (PGs), PCs, and PEs.

\section{ETHYLENE EFFECTS ON PRIMARY METABOLISM OF HARVESTED FRUITS}

The role of ethylene has long been recognized as a critical factor regulating ripening and senescence, and subsequently the storage life, of an array of horticultural commodities (Abeles et al., 1992; Saltveit, 1999; Tucker et al., 2017). Ethylene can affect the quality of these crops either when produced endogenously, or exogenously either applied to positively affect a biological factor, or as a contaminant. Low temperature and CA/MA affect product quality beneficially by decreasing metabolic activity in part by reducing ethylene production and action.

Fruits have traditionally been separated into two distinct groups, climacteric and non-climacteric. In climacteric fruits (and fruit vegetables) such as apple, avocado, banana, pear, and tomato, ripening is associated with an increase in respiratory activity that is associated with autocatalytic production of ethylene. Climacteric fruit, if harvested when mature, continue to ripen. In contrast, the respiration rates of non-climacteric fruits such as citrus, strawberry, and grape, decline during ripening with no autocatalytic ethylene production, and coordinated ripening changes do not take place after harvest. However, both climacteric and nonclimacteric fruits respond to ethylene, but in very distinct ways that can be used as diagnostic tools (Wills and Golding, 2016). When progressively higher ethylene concentrations are applied to climacteric fruits, the size of the respiratory peak remains similar, but the timing of the respiratory maximum (and ripening) is accelerated even after treatment stops. In a nonclimacteric fruit, respiration rates are proportionally greater as the ethylene concentration is increased but timing of the peak is not affected, and respiration decreases as soon as ethylene is removed. The rate of ripening is not necessarily a function of ripening type: non-climacteric fruits such as sweet cherries and strawberry can ripen rapidly, while citrus ripen slowly; climacteric fruits such as avocados and pears ripen rapidly, while certain apple cultivars ripen slowly.

However, a strict distinction between climacteric and nonclimacteric fruits is less clear than originally thought (Paul et al., 2012). Fruit types that have both ripening patterns include melon and plums (Abdi et al., 1997; Fernandez-Trujillo et al., 2008; Farcuh et al., 2019). It has long been thought that the ripening of climacteric fruits is regulated by ethylene while that of nonclimacteric fruits is regulated by abscisic acid (ABA) (Jia et al., 2011; Jia et al., 2013). However, it is clear that ethylene and ABA, 
as well as other hormones (e.g. auxins), are involved in ripening of both types of fruits (Manganaris et al., 2011; Li et al., 2019). Climacteric and non-climacteric types also share many aspects of ethylene perception and signaling and interestingly, the EThylene Receptor (ETR) gene is more abundant in climacteric fruit than non-climacteric fruits, and ETR accumulates earlier in the latter (Chen et al., 2018).

The involvement of ethylene in primary metabolism has been explored in many ways that include investigations into metabolism of normally ripening fruits, use of mutants or transgenic approaches, ethylene treatment of fruits with ethylene [directly as a gas or by use of ethylene releasing agents such as 2-chloroethylphosphonic acid (ethephon)], and ethylene analogues such as propylene. Ethylene antagonists such as silver and 1-MCP also have been used; of the two, 1-MCP has been especially useful for researchers due to its non-toxic nature, gaseous form at physiological temperatures, and its effectiveness at low concentrations (Sisler and Serek, 2003; Watkins, 2015). Although ethylene concentrations around fruits can also be lowered by methods such as ventilation, avoidance, and absorbers and oxidizers (Martinez-Romero et al., 2007), there is little information about their effects on primary metabolism.

In general, application of ethylene to climacteric fruits accelerates the rate of ripening (Saltveit, 1999), while 1-MCP decreases the rate of ripening, and in some cases can totally inhibit it (Watkins, 2006; Watkins, 2015). However, 1-MCP induces variable responses in different climacteric fruit species and even in cultivars of the same species (Watkins, 2015). Ethylene biosynthetic and signal transduction pathways of apples and peaches are differentially affected by 1-MCP action (Dal Cin et al., 2006). 1-MCP can also affect various ripening/ senescence processes of non-climacteric fruits (Huber, 2008; Li D. et al., 2016; Kafkaletou et al., 2019).

Non-targeted genomic, proteomic, and metabolomic approaches have revealed a number of changes in primary metabolism in response to ripening, exogenous ethylene, and ethylene inhibitors (Giovannoni et al., 2017; Li et al., 2017; Zhao X. et al., 2019). In nectarines, about $30 \%$ of the transcriptome corresponded to genes involved in primary metabolism and response processes related to ethylene, auxin, and other hormones (Ziliotto et al., 2008). In 1-MCP-treated fruits, altered transcript accumulation was detected for some genes with roles in ripening-related events including sugar metabolism. Changes in proteins of apples during ripening revealed enzymes involved in gluconeogenesis, C-compounds and carbohydrate metabolism, electron transport/energy production, and malic acid metabolism. Proteins involved in several multiple metabolic pathways, including glycolysis and the pentose-phosphate pathway were down-regulated, especially during the climacteric burst in respiration and during the senescent stage (Shi et al., 2014). In peaches, 34\% of differential protein expression in response to 1-MCP and ethephon were associated with pathways involved in energy and general metabolism (Zhang et al., 2012). In CA-stored "Empire" apples, most carbohydrates and organic acids were not appreciably affected by 1-MCP treatment, but levels of sorbitol and some amino acids were elevated toward the end of storage in treated fruit (Lee et al., 2012).

\section{Carbohydrate Metabolism}

Most research on the effects of ethylene on starch metabolism in fruit has been performed on bananas, and to a lesser extent on apples and kiwifruits. Starch degradation and sucrose synthesis are both developmentally regulated at transcriptional level (Janssen et al., 2008; Xiao et al., 2018; Zhang et al., 2018; Yan et al., 2019). Examples include kiwifruits, where analysis of the regulatory effects of differentially expressed genes identified a zinc finger TF, DNA BINDING WITH ONE FINGER (AdDof3), which showed significant transactivation on the AdBAM3L ( $\beta$ amylase) promoter (Zhang et al., 2018). In apples, ethylene biosynthesis is inhibited in the antisense-suppressed MADS8as-9 line; ethylene application to this line partially stimulated ripening, with starch degradation and other late ripening processes not being complete (Ireland et al., 2014).

Starch hydrolysis in bananas was enhanced by treatment with propylene or ethylene (Saraiva et al., 2018). Starch hydrolysis in apples can be dependent or independent of ethylene concentration, whether exogenous or endogenous (Thammawong and Arakawa, 2007; Doerflinger et al., 2015a). Postharvest 1-MCP effects on starch hydrolysis in apples also can be cultivar-dependent (Fan et al., 1999; Neuwald et al., 2010; Thammawong and Arakawa, 2010; Doerflinger et al., 2015b). In bananas, 1-MCP delays hydrolysis in a dose- and cultivardependent manner (Nascimento et al., 1997; Mainardi et al., 2006). Variation of responses to ethylene in different fruit types and cultivars may be explained by differences in sensitivity (Johnston et al., 2009); initiation of starch hydrolysis is ethylene sensitive and therefore even a very small increase in ethylene concentration can trigger the onset of starch hydrolysis. However, once initiated its hydrolysis is relatively independent of ethylene concentrations within the fruit tissue. Also, relationships between ethylene and starch metabolism are not straightforward, as starch degradation in bananas, for example, is coordinated with that of cell wall softening (Shiga et al., 2011).

Simultaneous synthesis and degradation of sucrose during postharvest storage of fruits has been well described (Duque et al., 1999; Zhu et al., 2013). A link between ethylene and sucrose metabolism is suggested by increased gene transcript and enzymatic activity of SPS by exogenous ethylene treatment or during postharvest ripening (Duque et al., 1999; Choudhury et al., 2008; Lombardo et al., 2011). Sucrose treatment of tomato fruits advanced ripening, and increased expression of genes involved in both sugar biosynthesis and degradation ( $\mathrm{Li} \mathrm{L}$. et al., 2016). The ETR transcripts accumulated earlier in nonclimacteric than in climacteric fruits, and this expression coincided with the onset of sugar accumulation (Chen et al., 2018). Investigations with "Micro-Tom" tomatoes and five hormone mutants (namely $d p y$, not, dgt, epi, and pro) indicated that ethylene plays an important role in regulation of sugar accumulation (Li et al., 2019). 
A feature of 1-MCP-treated apples is the low sucrose contents compared with the controls (Defilippi et al., 2004; Bekele et al., 2015). Bekele et al. (2015) suggested that low sucrose was due to temperature mediated activation of sucrose degrading enzymes and suppression of SPS activity by 1-MCP treatment, whereas in untreated fruit, the breakdown of sucrose did not result in accumulation of glucose due to its utilization to sustain a high respiration rates. However, 1-MCP treatment increased SuSy expression associated with the sucrose-sucrose cycle in "Royal Gala” apples (Storch et al., 2017). It was suggested that in the absence of ethylene, the fruit resumes a set of metabolic activities that were suppressed during ripening in the presence of ethylene. Sucrose contents are also lower in fruit from trees with downregulated 1-aminocyclopropane-1-carboxylic acid (ACC)synthase or ACC-oxidase enzyme activity, but contents could be restored to similar levels as wild type after exposure to ethylene (Defilippi et al., 2004).

Although grapes as non-climacteric fruits are thought to be ethylene independent, 1-MCP treatment resulted in lower sucrose accumulation in berries than in untreated fruit (Chervin et al., 2006). Decreased sucrose accumulation was associated with a down-regulation of two sucrose transporters (SUC11 and SUC12), whose expression is triggered at veraison when grape berries start to accumulate sugars. In citrus, 1-MCP repressed genes involved in starch synthesis and degradation and increased the expression levels of SuSy genes (Estables-Ortiz et al., 2016). In grapes, and another non-climacteric fruit, strawberry, it has been proposed that sucrose functions as a signal that acts upstream of the ABA signaling pathway, thus playing an important role in the regulation of fruit ripening (Jia et al., 2013; Jia et al., 2017).

A mutant series of Japanese plums exhibits three distinct ripening patterns: climacteric, suppressed-climacteric, and nonclimacteric (Minas et al., 2015). "Santa Rosa," which is climacteric, and its bud-sport mutant "Sweet Miriam," which is non-climacteric, have been used to investigate sugar metabolism. At the ripe stage, non-climacteric fruits accumulate higher sorbitol than that of climacteric fruits (Kim et al., 2015; Farcuh et al., 2017; Farcuh et al., 2018). Higher sorbitol contents in "Sweet Miriam" were associated with decreased activity and expression of $\mathrm{NAD}^{+}$-dependent sorbitol dehydrogenase and sorbitol oxidase and increased sorbitol-6-phosphate dehydrogenase activity, as well as increased sucrose catabolism (Kim et al., 2015). Enhanced sorbitol synthesis and lower sucrose, glucose, and fructose contents were also found during on-tree ripening of the non-climacteric "Sweet Miriam" than in the climacteric "Santa Rosa" (Farcuh et al., 2017); contents of the minor sugars galactinol, raffinose, myo-inositol, and trehalose also increased in "Sweet Miriam," while that of galactose was higher in "Santa Rosa." The effects of ethylene on sugar metabolism were studied using propylene and 1-MCP (Farcuh et al., 2018). Ethylene increased biosynthesis of sucrose while decreasing that of sorbitol. Decreased and increased sucrose and fructose accumulation may result from sorbitol and sucrose catabolism in climacteric and non-climacteric fruits, respectively. Ethylene resulted in galactose accumulation in "Santa Rosa"; galactose has been also reported to stimulate ethylene production in tomato fruits (Kim et al., 1987).

\section{Organic Acids}

A general pattern of organic acid contents of fruits during development, is an initial accumulation of acids followed by a decrease of contents either by increasing fruit mass or metabolism as a function of synthesis, degradation, and compartmentalization. The acids are sequestered in the vacuoles and released to provide substrate for increased respiration during ripening of climacteric fruits, meet higher energy demand in non-climacteric fruits, and produce hexoses by gluconeogenesis (Beruter, 2004; Sweetman et al., 2009). Influx and efflux of malic acid from the vacuole may vary over time (Walker et al., 2015; Famiani et al., 2016b). In peaches, contributions of malic and citric acids to metabolism are negligible, and it is likely that gluconeogenesis occurs during ripening (Famiani et al., 2016b). In ripening of grapes, a nonclimacteric fruit, decreased malic acid contents were associated with metabolism, but to a lesser extent compared with sugars (Famiani et al., 2016a). Overall, there is a diversity of responses of different fruits to ethylene and the contribution of stored organic acids to metabolism is not well understood. Organic acid metabolism is not directly linked to respiratory and climacteric characteristics of the fruit, however, interactions between organic acid metabolism and hormone signaling provide useful insights for future research (Batista-Silva et al., 2018).

Detailed studies exploiting 1-MCP to investigate organic acid metabolism are recent. In apples, 1-MCP slowed the decreases of malic and citric acid contents during ripening at $20^{\circ} \mathrm{C}$ by regulating organic acid metabolism (Liu et al., 2016). In addition, up-regulation of $M d P E P C$ and $M d c y M D H$ expression, higher PEPC and cyNAD-MDH activities, and the decreased malate degradation via limiting MdPEPCK expression with lower activity of PEPCK were reported. 1-MCP treatment up-regulated acid transport genes, including $M d V H A-A$, $M d V H P$, and $M a 1$, resulting in higher malic acid contents in the vacuole (Liu et al., 2016). In Asian pears, decreasing malic acid contents during ripening were associated with downregulation of genes associated with malic acid metabolism, lower cyNAD-MDH, and higher cyNADP-MDH activity (Wang et al., 2018). 1-MCP-treated fruits had higher malic acid contents, upregulated gene expression, higher NADdependent malate dehydrogenase activity, and lower NADPME-dependent malate dehydrogenase activity.

\section{Amino Acids and Lipids}

Amino acid contents typically decrease during ripening and storage, often associated with secondary pathways that produce aroma volatiles, particularly esters, because of the close linkages with ethylene production during ripening (Giovannoni et al., 2017). 1-MCP treatments of fruits can maintain higher amino acid contents (Lee et al., 2012; Zhang et al., 2014; Bekele et al., 2015) that could result from a reduced utilization in metabolic 
processes. Amino acids may also be involved in fruit responses to stress and development of physiological disorders associated with 1-MCP treatment through their role as substrate for compounds such as GABA (Flaherty et al., 2018b). They are also directly linked to many secondary metabolic processes, most notably production of aroma volatiles, several groups of which are related to amino acid and fatty acid metabolism.

Loss of membrane function with changes in membrane lipids, particularly their degree of unsaturation, is a feature of ripening and senescence (Marangoni et al., 1996). These changes lead to altered membrane properties and result in defects such as ion leakage and loss of cellular compartmentalization, and therefore represent an obvious consequence of ethylene production. The literature on these changes outside of the effects of imposed postharvest treatments such as low temperature and CA/MA is limited. While 1-MCP has been used to investigate the effects of ethylene on lipids it is not surprising that the results typically show slowing down of changes associated with ripening and senescence. In fruits such as kiwifruit, pear, pitaya, and tomato, 1-MCP inhibited lipid associated changes such as increases of membrane permeability, lipid peroxidation, the decrease of unsaturated fatty acids and PLD gene expression (Dek et al., 2018; Huang et al., 2019; Tao et al., 2019; Xu et al., 2019).

\section{FINAL REMARKS AND FUTURE PERSPECTIVES}

Storage protocols are based on the application of controlled stresses or treatments aimed at delaying genetically programmed fruit ripening and the onset of senescence by affecting primary metabolism.

This review highlights a number of issues specifically dealing with the effects of three main post-harvest physical and chemical factors on the primary metabolic processes of stored fruits. The effects of these protocols depend on a number of factors including the intensity and duration of the applied protocol, the fruit type and cultivar, the maturity and ripening stage at harvest, as well as pre-harvest conditions. Considering the impact of pre-harvest factors, the information available concerns solely the effects of specific treatments and protocols (e.g. spraying with chemicals, controlling crop load, fertilization, water management) on the fruit responses in terms of shelf-life, technological parameters and the incidence of decay and disorders, with no specific information regarding primary metabolic pathways.

An extensive literature on ethylene and our understanding of its involvement in ripening of both non-climacteric and climacteric fruits has been developed. Transgenic and 1-MCP treatments have become powerful tools to investigate the role of ethylene on primary metabolism. Segregation of fruits based on ripening patterns are less strict than previously assumed and cross talk among hormones other than ethylene, has been identified. The interactions between ethylene signaling and sugars also is an especially active area, while there is a paucity of information about organic acids, amino acids and lipids. Studies concerning postharvest treatments such as low temperature and the effects of CA/MA have centered more on injuries associated with these treatments rather than on the effect of these treatments on non-injurious metabolism. High variability of responses associated with different genotypes to an array of postharvest treatments, often used in an integrated manner, renders difficult to identify primary metabolic changes occurring in fruit tissues in contrast to model systems.

The increasing availability of genome sequencing of different genotypes, and the development of "omics" techniques are providing tools to overcome these limitations, and thereby better understand and clarify the fundamental mechanism regulating the postharvest metabolic responses. These tools are also providing opportunities to exploit findings that are, so far, mainly based on model systems. This is the case of low oxygen and high carbon dioxide postharvest stress physiology studies. Recent reports describe the role of specific transcription factors (TFs) such as ethylene-responsive factors (ERFs), in synergy with WRKY and MYB elements, in controlling the expression of $P D C$ gene promoter in persimmons under high carbon dioxide/ hypoxia (Zhu et al., 2018; Zhu et al., 2019). Specific and multiple TFs of different clades/classes and a TF regulatory network are involved in the responses to such storage conditions that induce marked changes of primary metabolism gene expression. $A D H$ and $P D C$, belonging to the core responsive genes of plants to low oxygen conditions (Mustroph et al., 2009), are controlled by ERFs in Arabidopsis, through a fine-tuned mechanism ( $\mathrm{N}$-end rule pathway, NERP) of oxygen sensing (Gibbs et al., 2011; Licausi et al., 2011). ADH and PDC enzymes are involved in primary (fermentative) metabolism and play a major role in the determination of fruit flavor and aroma. In apples, a specific ERF protein (MdRAP2.12) has been shown to differentially accumulate at different oxygen concentrations, suggesting that the oxygen-sensing mechanisms described in Arabidopsis are also present in apple fruit (Cukrov et al., 2016). The variable responses in terms of the primary metabolism compound (pyruvate, alanine, ethanol) accumulation observed in different apple cultivars under hypoxic conditions might be the result of the selective activation and specific organization of ERF-based sensing mechanisms (Brizzolara et al., 2017).

An additional field of investigation involves the tolerance of fruits to cold stress occurring during storage. Cold-stored fruits re-direct their metabolism, starting from changes in gene expression, with different levels of tolerance to cold stress depending on the genetic background. A number of coldresponsive (COR) genes have been identified in vegetative tissues of model species, some of them involved in physiological and biochemical changes during the process of cold acclimation and tolerance. COR genes have been identified also in different fruit species such as peaches where their expression has been analyzed in relation to different behavior of CI sensitive and CI non-sensitive cultivars during refrigerated storage (Bustamante et al., 2016; Nilo-Poyanco et al., 2019). 
Selective changes in expression of genes related to energy and stress response, amino acid, carbohydrate, lipid, and specialized metabolism have been observed (Zhang et al., 2010; Pons et al., 2014; Pons et al., 2016) with C-repeat-binding factors (CBFs) apparently playing a key role in modulating the expression (Liang et al., 2013).

Elucidation of these regulatory mechanisms will widen our understanding on primary metabolic, and associated secondary, responses of fruit tissues of harvested fruits, and also help to

\section{REFERENCES}

Abdi, N., Holford, P., McGlasson, W. B., and Mizrahi, Y. (1997). Ripening behaviour and responses to propylene in four cultivars of Japanese type plums. Postharv. Biol. Technol. 12, 21-34. doi: 10.1016/s0925-5214(97) 00041-0

Abeles, F. B. M., Morgan, P. W., and Saltveit, M. E. (1992). Ethylene in Plant Biology (San Diego, CA: Academic Press).

Ampofo-Asiama, J., Baiye, V. M. M., Hertog, M., Waelkens, E., Geeraerd, A. H., and Nicolai, B. M. (2014). The metabolic response of cultured tomato cells to low oxygen stress. Plant Biol. 16, 594-606. doi: 10.1111/plb.12094

Angioni, A., Pirisi, F., Caboni, P., D'Aquino, S., Fadda, A., and Schirra, M. (2011). Effects of cold storage on quality traits of Sardinian myrtle (Myrtus communis L.) berries and their alcoholic extracts. J. Agric. Sci. Technol. B. 1, 790-798.

António, C., Papke, C., Rocha, M., Diab, H., Limami, A. M., Obata, T., et al. (2016). Regulation of primary metabolism in response to low oxygen availability as revealed by carbon and nitrogen isotope redistribution. Plant Physiol. 170, 4356. doi: 10.1104/pp.15.00266

Atkin, O. K., and Tjoelker, M. G. (2003). Thermal acclimation and the dynamic response of plant respiration to temperature. Trends Plant Sci. 8, 343-351. doi: 10.1016/S1360-1385(03)00136-5

Bailey-Serres, J., Fukao, T., Gibbs, D. J., Holdsworth, M. J., Lee, S. C., Licausi, F., et al. (2012). Making sense of low oxygen sensing. Trends Plant Sci. 17, 129138. doi: 10.1016/j.tplants.2011.12.004

Bang, J., Lim, S., Yi, G., Lee, J. G., and Lee, E. J. (2019). Integrated transcriptomicmetabolomic analysis reveals cellular responses of harvested strawberry fruit subjected to short-term exposure to high levels of carbon dioxide. Postharv. Biol. Technol. 148, 120-131. doi: 10.1016/j.postharvbio.2018.11.003

Bartley, I. M. (1986). Changes in sterol and phospholipid composition of apples during storage at low temperature and low oxygen concentration. J. Sci. Food Agric. 37, 31-36. doi: 10.1002/jsfa.2740370105

Batista-Silva, W., Nascimento, V. L., Medeiros, D. B., Nunes-Nesi, A., Ribeiro, D. M., Zsogon, A., et al. (2018). Modifications in organic acid profiles during fruit development and ripening: correlation or causation? Front. Plant Sci. 9, 1689. doi: 10.3389/fpls.2018.01689

Bekele, E. A., Beshir, W. F., Hertog, M., Nicolai, B. M., and Geeraerd, A. H. (2015). Metabolic profiling reveals ethylene mediated metabolic changes and a coordinated adaptive mechanism of 'Jonagold' apple to low oxygen stress. Physiol. Plant 155, 232-247. doi: 10.1111/ppl.12351

Bekele, E. A., Ampofo-Asiama, J., Alis, R. R., Hertog, M., Nicolai, B. M., and Geeraerd, A. H. (2016). Dynamics of metabolic adaptation during initiation of controlled atmosphere storage of 'Jonagold' apple: effects of storage gas concentrations and conditioning. Postharv. Biol. Technol. 117, 9-20. doi: 10.1016/j.postharvbio.2016.02.003

Beruter, J. (2004). Carbohydrate metabolism in two apple genotypes that differ in malate accumulation. J. Plant Physiol. 161, 1011-1029. doi: 10.1016/ j.jplph.2003.12.008

Bessemans, N., Verboven, P., Verlinden, B. E., and Nicolai, B. M. (2016). A novel type of dynamic controlled atmosphere storage based on the respiratory quotient (RQ-DCA). Postharv. Biol. Technol. 115, 91-102. doi: 10.1016/ j.postharvbio.2015.12.019

Boeckx, J., Hertog, M., Geeraerd, A., and Nicolai, B. (2019). Regulation of the fermentative metabolism in apple fruit exposed to low-oxygen stress reveals a optimize storage protocols with benefits in terms of reduced losses and improved consumer satisfaction.

\section{AUTHOR CONTRIBUTIONS}

All authors planned the structure of the review, contributed in writing the article, read and approved the submitted version. high flexibility. Postharv. Biol. Technol. 149, 118-128. doi: 10.1016/ j.postharvbio.2018.11.017

Brackmann, A., Streif, J., and Bangerth, F. (1993). Relationship between a reduced aroma production and lipid-metabolism of apples after long-term controlled atmosphere storage. J. Am. Soc. Hortic. Sci. 118, 243-247.

Brikis, C. J., Zarei, A., Chiu, G. Z., Deyman, K. L., Liu, J. Y., Trobacher, C. P., et al. (2018). Targeted quantitative profiling of metabolites and gene transcripts associated with 4-aminobutyrate (GABA) in apple fruit stored under multiple abiotic stresses. Hort. Res. 5(1), 1-14. doi: 10.1038/s41438-018-0069-3

Brizzolara, S., Santucci, C., Tenori, L., Hertog, M., Nicolai, B., Sturz, S., et al. (2017). A metabolomics approach to elucidate apple fruit responses to static and dynamic controlled atmosphere storage. Postharv. Biol. Technol. 127, 7687. doi: $10.1016 /$ j.postharvbio.2017.01.008

Brizzolara, S., Hertog, M., Tosetti, R., Nicolai, B., and Tonutti, P. (2018). Metabolic responses to low temperature of three peach fruit cultivars differently sensitive to cold storage. Front. Plant Sci. 9, 706. doi: 10.3389/fpls.2018.00706

Brizzolara, S., Cukrov, D., Mercadini, M., Martinelli, F., Ruperti, B., and Tonutti, P. (2019). Short term responses of apple fruit to partial reoxygenation during extreme hypoxic storage conditions. J. Agric. Food Chem. 67, 4754-4763. doi: 10.1021/acs.jafc.9b00036

Brown, D. J., and Beevers, H. (1987). Fatty acids of rice coleoptiles in air and anoxia. Plant Physiol. 84, 555-559. doi: 10.1104/pp.84.2.555

Brummell, D. A., Dal Cin, V., Lurie, S., Crisosto, C. H., and Labavitch, J. M. (2004). Cell wall metabolism during the development of chilling injury in cold-stored peach fruit: association of mealiness with arrested disassembly of cell wall pectins. J. Exp. Bot. 55, 2041-2052. doi: 10.1093/jxb/erh228

Bustamante, C. A., Monti, L. L., Gabilondo, J., Scossa, F., Valentini, G., Budde, C. O., et al. (2016). Differential metabolic rearrangements after cold storage are correlated with chilling injury resistance of peach fruits. Front. Plant Sci. 7, 1478. doi: 10.3389/ fpls.2016.01478

Bustamante, C. A., Brotman, Y., Monti, L. L., Gabilondo, J., Budde, C. O., Lara, M. V., et al. (2018). Differential lipidome remodeling during postharvest of peach varieties with different susceptibility to chilling injury. Physiol. Plant 163,2-17. doi: 10.1111/ ppl.12665

Cha, G. H., Prathibhani, H. M., Kumarihami, C., Kim, H. L., and Kwack, Y. B. (2019). Storage temperature influences fruit ripening and changes in organic acids of kiwifruit treated with exogenous ethylene. Hortic. Sci. Tech. 2019, 618629. doi: 10.7235/HORT.20190062

Chen, Y., Grimplet, J., David, K., Castellarin, S. D., Terol, J., Wong, D. C. J., et al. (2018). Ethylene receptors and related proteins in climacteric and nonclimacteric fruits. Plant Sci. 276, 63-72. doi: 10.1016/j.plantsci.2018.07.012

Chervin, C., Terrier, N., Ageorges, A., Ribes, F., and Kuapunyakoon, T. (2006). Influence of ethylene on sucrose accumulation in grape berry. Am. J. Enol. Viticult. 57, 511-513.

Choudhury, S. R., Roy, S., Das, R., and Sengupta, D. N. (2008). Differential transcriptional regulation of banana sucrose phosphate synthase gene in response to ethylene, auxin, wounding, low temperature and different photoperiods during fruit ripening and functional analysis of banana SPS gene promoter. Planta 229, 207-223. doi: 10.1007/s00425-008-0821-2

Cukrov, D., Zermiani, M., Brizzolara, S., Cestaro, A., Licausi, F., Luchinat, C., et al. (2016). Extreme hypoxic conditions induce selective molecular responses and metabolic reset in detached apple fruit. Front. Plant Sci. 7, 146. doi: 10.3389/ fpls.2016.00146 
Dal Cin, V., Rizzini, F. M., Botton, A., and Tonutti, P. (2006). The ethylene biosynthetic and signal transduction pathways are differently affected by 1MCP in apple and peach fruit. Postharv. Biol. Technol. 42, 125-133. doi: 10.1016/j.postharvbio.2006.06.008

Deewatthanawong, R., Nock, J. F., and Watkins, C. B. (2010a). g-Aminobutyric acid (GABA) accumulation in four strawberry cultivars in response to elevated $\mathrm{CO}_{2}$ storage. Postharv. Biol. Technol. 57, 92-96. doi: 10.1016/j.postharvbio. 2010.03.003

Deewatthanawong, R., Rowell, P., and Watkins, C. B. (2010b). g-Aminobutyric acid (GABA) metabolism in $\mathrm{CO}_{2}$ treated tomatoes. Postharv. Biol. Technol. 57, 97-105. doi: 10.1016/j.postharvbio.2010.03.007

Defilippi, B. G., Dandekar, A. M., and Kader, A. A. (2004). Impact of suppression of ethylene action or biosynthesis on flavor metabolites in apple (Malus domestica Borkh) fruits. J. Agric. Food Chem. 52, 5694-5701. doi: 10.1021/ if049504x

Dek, M. S. P., Padmanabhan, P., Subramanian, J., and Paliyath, G. (2018). Inhibition of tomato fruit ripening by $1-\mathrm{MCP}$, wortmannin and hexanal is associated with a decrease in transcript levels of phospholipase D and other ripening related genes. Postharv. Biol. Technol. 140, 50-59. doi: 10.1016/ j.postharvbio.2018.02.009

Diab, H., and Limami, A. M. (2016). Reconfiguration of N metabolism upon hypoxia stress and recovery: roles of alanine aminotransferase (AlaAT) and glutamate dehydrogenase (GDH). Plants-Basel 5(2), 25. doi: 10.3390/plants5020025

Doerflinger, F. C., Miller, W. B., Nock, J. F., and Watkins, C. B. (2015a). Relationships between starch pattern indices and starch concentrations in four apple cultivars. Postharv. Biol. Technol. 110, 86-95. doi: 10.1016/ j.postharvbio.2015.07.012

Doerflinger, F. C., Miller, W. B., Nock, J. F., and Watkins, C. B. (2015b). Variations in zonal fruit starch concentrations of apples - a developmental phenomenon or an indication of ripening? Hort. Res. 2(1), 1-9. doi: 10.1038/hortres.2015.47

Duque, P., Barreiro, M. G., and Arrabaca, J. D. (1999). Respiratory metabolism during cold storage of apple fruit. I. Sucrose metabolism and glycolysis. Physiologia Plantarum 107, 14-23. doi: 10.1034/j.1399-3054.1999.100103.x

Estables-Ortiz, B., Romero, P., Ballester, A. R., Gonzalez-Candelas, L., and Lafuente, M. T. (2016). Inhibiting ethylene perception with 1methylcyclopropene triggers molecular responses aimed to cope with cell toxicity and increased respiration in citrus fruits. Plant Physiol. Biochem. 103, 154-166. doi: 10.1016/j.plaphy.2016.02.036

Etienne, A., Genard, M., Lobit, P., Mbeguie-A-Mbeguie, D., and Bugaud, C. (2013). What controls fleshy fruit acidity? A review of malate and citrate accumulation in fruit cells. J. Exp. Bot. 64, 1451-1469. doi: 10.1093/jxb/ert035

Famiani, F., Farinelli, D., Frioni, T., Palliotti, A., Battistelli, A., Moscatello, S., et al. (2016a). Malate as substrate for catabolism and gluconeogenesis during ripening in the pericarp of different grape cultivars. Biol. Plant 60, 155-162. doi: 10.1007/s10535-015-0574-2

Famiani, F., Farinelli, D., Moscatello, S., Battistelli, A., Leegood, R. C., and Walker, R. P. (2016b). The contribution of stored malate and citrate to the substrate requirements of metabolism of ripening peach (Prunus persica L. Batsch) flesh is negligible. Implications for the occurrence of phosphoenolpyruvate carboxykinase and gluconeogenesis. Plant Physiol. Biochem. 101, 33-42. doi: 10.1016/j.plaphy.2016.01.007

Fan, X. T., Blankenship, S. M., and Mattheis, J. P. (1999). L-Methylcyclopropene inhibits apple ripening. J. Am. Soc. Hortic. Sci. 124, 690-695. doi: 10.21273/ JASHS.124.6.690

Farcuh, M., Li, B. S., Rivero, R. M., Shlizerman, L., Sadka, A., and Blumwald, E. (2017). Sugar metabolism reprogramming in a non-climacteric bud mutant of a climacteric plum fruit during development on the tree. J. Exp. Bot. 68, 58135828. doi: 10.1093/jxb/erx391

Farcuh, M., Rivero, R. M., Sadka, A., and Blumwald, E. (2018). Ethylene regulation of sugar metabolism in climacteric and non-climacteric plums. Postharv. Biol. Technol. 139, 20-30. doi: 10.1016/j.postharvbio.2018.01.012

Farcuh, M., Toubiana, D., Sade, N., Rivero, R. M., Doron-Faigenboim, A., Nambara, E., et al. (2019). Hormone balance in a climacteric plum fruit and its non-climacteric bud mutant during ripening. Plant Sci. 280, 51-65. doi: 10.1016/j.plantsci.2018.11.001

Fernandez-Trujillo, J. P., Nock, J. F., and Watkins, C. B. (1999). Fermentative metabolism and organic acid concentrations in fruit of selected strawberry cultivars with different tolerances to carbon dioxide. J. Am. Soc. Hortic. Sci. 124, 696-701. doi: 10.21273/JASHS.124.6.696

Fernandez-Trujillo, J. P., Obando-Ulloa, J. M., Martinez, J. A., Moreno, E., GarciaMas, J., and Monforte, A. J. (2008). Climacteric and non-climacteric behavior in melon fruit 2. Linking climacteric pattern and main postharvest disorders and decay in a set of near-isogenic lines. Postharv. Biol. Technol. 50, 125-134. doi: 10.1016/j.postharvbio.2008.04.007

Flaherty, E. J., DeEll, J. R., She, B. J., and Bozzo, G. G. (2018a). 1-Methylcyclopropene affects the shelf-life quality of controlled atmosphere stored 'Cold Snap ${ }^{\text {TM, }}$ pears. Can. J. Plant Sci. 98, 1365-1375. doi: 10.1139/cjps-2018-0136

Flaherty, E. J., Lum, G. B., DeEll, J. R., Subedi, S., Shelp, B. J., and Bozzo, G. G. (2018b). Metabolic alterations in postharvest pear fruit as influenced by 1methylcyclopropene and controlled atmosphere storage. J. Agric. Food Chem. 66, 12989-12999. doi: 10.1021/acs.jafc.8b04912

Galili, G. (2011). The aspartate-family pathway of plants: linking production of essential amino acids with energy and stress regulation. Plant Signaling Behav. 6, 192-195. doi: 10.4161/psb.6.2.14425

Gao, Y., Kan, C. N., Wan, C. P., Chen, C. Y., Chen, M., and Chen, J. Y. (2018). Effects of hot air treatment and chitosan coating on citric acid metabolism in ponkan fruit during cold storage. PloS One 13, 11. doi: 10.1371/ journal.pone.020658E

Gasser, F., Eppler, T., Naunheim, W., Gabioud, S., and Hohn, E. (2008). Control of the critical oxygen level during dynamic CA storage of apples. Agrarforschung 15, 98-103. doi: 10.17660/ActaHortic.2008.796.6

Geigenberger, P. (2003). Response of plant metabolism to too little oxygen. Curr. Opin. In Plant Biol. 6, 247-256. doi: 10.1016/s1369-5266(03)00038-4

Gibbs, D. J., Lee, S. C., Isa, N. M., Gramuglia, S., Fukao, T., Bassel, G. W., et al. (2011). Homeostatic response to hypoxia is regulated by the N-end rule pathway in plants. Nature 479, 415-U172. doi: 10.1038/nature10534

Giovannoni, J., Nguyen, C., Ampofo, B., Zhong, S. L., and Fei, Z. J. (2017). The epigenome and transcriptional dynamics of fruit ripening. Annu. Rev. Plant Biol. 68, 61-84. doi: 10.1146/annurev-arplant-042916-040906

Gonzalez, C., Zanor, M. I., Re, M. D., Otaiza, S., Asis, R., Valle, E. M., et al. (2019). Chilling tolerance of Micro-Tom fruit involves changes in the primary metabolite levels and in the stress response. Postharv. Biol. Technol. 148, 5867. doi: 10.1016/j.postharvbio.2018.10.010

Gonzalez-Aguero, M., Cifuentes-Esquivel, N., Ibanez-Carrasco, F., Gudenschwager, O., Campos-Vargas, R., and Defilippi, B. G. (2011). Identification and characterization of genes differentially expressed in cherimoya (Annona cherimola Mill) after exposure to chilling injury conditions. J. Agric. Food Chem. 59, 13295-13299. doi: 10.1021/jf203583t

Gonzalez-Meler, M. A., Ribas-Carbo, M., Siedow, J. N., and Drake, B. G. (1996). Direct inhibition of plant mitochondrial respiration by elevated $\mathrm{CO}_{2}$. Plant Physiol. 112, 1349-1355. doi: 10.1104/pp.112.3.1349

Gorin, N., Bonisolli, F., Heidema, F. T., Klop, W., and Williams, A. A. (1978). Changes in starch content and amylase zymograms during storage of golden delicious and Cox's orange pippin apples. Z. Lebensm. Unters. Forsch. 166, 157-161. doi: 10.1007/BF01354808

Gross, K. C., Wang, C. Y., and Saltveit, M. E. (2016). The Commercial Storage of Fruits, Vegetables, and Florist and Nursery Stocks. USDA HB 66 http://www. ba.ars.usda.gov/hb66/index.html.

Halder-Doll, H., and Bangerth, F. (1987). Inhibition of autocatalytic $\mathrm{C}_{2} \mathrm{H}_{4}$ biosynthesis by AVG applications and consequences on the physiological behavior and quality of apple fruits in cool storagE. Sci. Hortic. 33, 87-96. doi: 10.1016/0304-4238(87)90035-5

Harwood, J. L. (1987). Phosphoglycerides of mitochondrial membranes. Methods In Enzymol. 148, 475-485. doi: 10.1016/0076-6879(87)48046-4

Harwood, J. L. (1988). Fatty acid metabolism. Annu. Rev. Plant Physiol. Plant Mol. Biol. 39, 101-138. doi: 10.1146/annurev.arplant.39.1.101

Hatoum, D., Annaratone, C., Hertog, M., Geeraerd, A. H., and Nicolai, B. M. (2014). Targeted metabolomics study of 'Braeburn' apples during long-term storage. Postharv. Biol. Technol. 96, 33-41. doi: 10.1016/ j.postharvbio.2014.05.004

Hatoum, D., Hertog, M., Geeraerd, A. H., and Nicolai, B. M. (2016). Effect of browning related pre- and postharvest factors on the 'Braeburn' apple metabolome during CA storage. Postharv. Biol. Technol. 111, 106-116. doi: 10.1016/j.postharvbio.2015.08.004 
Hill, C. B., Jha, D., Bacic, A., Tester, M., and Roessner, U. (2013). Characterization of ion contents and metabolic responses to salt stress of different Arabidopsis AtHKT1;1 genotypes and their parental strains. Mol. Plant 6, 350-368. doi: $10.1093 / \mathrm{mp} / \mathrm{sss} 125$

Ho, Q. T., Verboven, P., Verlinden, B. E., Schenk, A., and Nicolaï, B. M. (2013). Controlled atmosphere storage may lead to local ATP deficiency in apple. Postharv. Biol. Technol. 78, 103-112. doi: 10.1016/j.postharvbio.2012.12.014

Holland, N., Sala, J. M., Menezes, H. C., and Lafuente, M. T. (1999). Carbohydrate content and metabolism as related to maturity and chilling sensitivity of $\mathrm{cv}$. Fortune mandarins. J. Agric. Food Chem. 47, 2513-2518. doi: 10.1021/ jf981402h

Holland, N., Menezes, H. C., and Lafuente, M. T. (2002). Carbohydrates as related to the heat-induced chilling tolerance and respiratory rate of 'Fortune' mandarin fruit harvested at different maturity stages. Postharv. Biol. Technol. 25, 181-191. doi: 10.1016/s0925-5214(01)00182-x

Holland, N., Menezes, H. C., and Lafuente, M. T. (2005). Carbohydrate metabolism as related to high-temperature conditioning and peel disorders occurring during storage of citrus fruit. J. Agric. Food Chem. 53, 8790-8796. doi: $10.1021 /$ jf051293o

Huang, H., Guo, L. F., Wang, L., Wang, H., Ma, S. M., Jiang, Y. M., et al. (2019). 1Methylcyclopropene (1-MCP) slows ripening of kiwifruit and affects energy status, membrane fatty acid contents and cell membrane integrity. Postharv. Biol. Technol. 156, 110941. doi: 10.1016/j.postharvbio.2019.110941

Huber, D. J. (2008). Suppression of ethylene responses through application of 1methylcyclopropene: a powerful tool for elucidating ripening and senescence mechanisms in climacteric and nonclimacteric fruits and vegetables. HortScience 43, 106-111. doi: 10.21273/HORTSCI.43.1.106

Hyun, T. K., Eom, S. H., Jeun, Y. C., Han, S. H., and Kim, J. S. (2013). Identification of glutamate decarboxylases as a gamma-aminobutyric acid (GABA) biosynthetic enzyme in soybean. Ind. Crops Prod. 49, 864-870. doi: 10.1016/ j.indcrop.2013.06.046

Ireland, H. S., Gunaseelan, K., Muddumage, R., Tacken, E. J., Putterill, J., Johnston, J. W., et al. (2014). Ethylene regulates apple (Malus $x$ domestica) fruit softening through a dose $\mathrm{x}$ time-dependent mechanism and through differential sensitivities and dependencies of cell wall-modifying genes. Plant Cell Physiol. 55, 1005-1016. doi: 10.1093/pcp/pcu034

Janssen, B. J., Thodey, K., Schaffer, R. J., Alba, R., Balakrishnan, L., Bishop, R., et al. (2008). Global gene expression analysis of apple fruit development from the floral bud to ripe fruit. BMC Plant Biol. 8, 16. doi: 10.1186/1471-2229-8-16

Jia, H.-F., Chai, Y.-M., Li, C.-L., Lu, D., Luo, J.-J., Qin, L., et al. (2011). Abscisic acid plays an important role in the regulation of strawberry fruit ripening. Plant Physiol. 157, 188-199. doi: 10.1104/pp.111.177311

Jia, H., Wang, Y., Sun, M., Li, B., Han, Y., Zhao, Y., et al. (2013). Sucrose functions as a signal involved in the regulation of strawberry fruit development and ripening. New Phytol. 198, 453-465. doi: 10.1111/nph.12176

Jia, H. F., Xie, Z. Q., Wang, C., Shangguan, L. F., Qian, N., Cui, M. J., et al. (2017). Abscisic acid, sucrose, and auxin coordinately regulate berry ripening process of the Fujiminori grape. Funct. Integr. Genomics 17, 441-457. doi: 10.1007/ s10142-017-0546-z

Johnston, J. W., Gunaseelan, K., Pidakala, P., Wang, M., and Schaffer, R. J. (2009). Coordination of early and late ripening events in apples is regulated through differential sensitivities to ethylene. J. Exp. Bot. 60, 2689-2699. doi: 10.1093/ jxb/erp122

Kafkaletou, M., Fasseas, C., and Tsantili, E. (2019). Increased firmness and modified cell wall composition by ethylene were reversed by the ethylene inhibitor 1-methylcyclopropene (1-MCP) in the non-climacteric olives harvested at dark green stage - possible implementation of ethylene for olive quality. J. Plant Physiol. 238, 63-71. doi: 10.1016/j.jplph.2019.05.006

Kanellis, A. K., Tonutti, P., and Perata, P. (2009). "Biochemical and molecular aspects of modified and controlled atmospheres," in Modified and controlled atmospheres for the storage, transportation, and packaging of horticultural commodities. Eds. E. M. Yahia (Boca Raton, Florida, U. S. A.: CRC Press), 553-567.

Kim, J. K., Gross, K. C., and Solomos, T. (1987). Characterization of the stimulation of ethylene production by galactose in tomato (Lycopersicon esculentum Mill) fruit. Plant Physiol. 85, 804-807. doi: 10.1104/pp.85.3.804

Kim, H. Y., Farcuh, M., Cohen, Y., Crisosto, C., Sadka, A., and Blumwald, E. (2015). Non-climacteric ripening and sorbitol homeostasis in plum fruits. Plant Sci. 231, 30-39. doi: 10.1016/j.plantsci.2014.11.002
Lara, M. V., Budde, C. O., Porrini, L., Borsani, J., Murray, R., Andreo, C. S., et al. (2011). Peach (Prunus persica) fruit response to anoxia: reversible ripening delay and biochemical changes. Plant Cell Physiol. 52, 392-403. doi: 10.1093/ $\mathrm{pcp} / \mathrm{pcq} 200$

Lauxmann, M. A., Borsani, J., Osorio, S., Lombardo, V. A., Budde, C. O., Bustamante, C. A., et al. (2014). Deciphering the metabolic pathways influencing heat and cold responses during post-harvest physiology of peach fruit. Plant Cell Environ. 37, 601-616. doi: 10.1111/pce.12181

Lee, J., Rudell, D. R., Davies, P. J., and Watkins, C. B. (2012). Metabolic changes in 1-methylcyclopropene (1-MCP)-treated 'Empire' apple fruit during storage. Metabolomics 8, 742-753. doi: 10.1007/s11306-011-0373-5

Leisso, R. S., Buchanan, D. A., Lee, J., Mattheis, J. P., Sater, C., Hanrahan, I., et al. (2015). Chilling-related cell damage of apple (Malus x domestica Borkh.) fruit cortical tissue impacts antioxidant, lipid and phenolic metabolism. Physiol. Plant 153, 204-220. doi: 10.1111/ppl.12244

Li, D. D., Mou, W. S., Wang, Y. S., Li, L., Mao, L. C., Ying, T. J., et al. (2016). Exogenous sucrose treatment accelerates postharvest tomato fruit ripening through the influence on its metabolism and enhancing ethylene biosynthesis and signaling. Acta Physiol. Plant 38(9), 225. doi: 10.1007/s11738-016-2240-5

Li, L., Lichter, A., Chalupowic, D., Gamrasni, D., Goldberg, T., Nerya, O., et al. (2016). Effects of the ethylene-action inhibitor 1-methylcyclopropene on postharvest quality of non-climacteric fruit crops. Postharv. Biol. Technol. 111, 322-329. doi: 10.1016/j.postharvbio.2015.09.031

Li, L., Ban, Z., Limwachiranon, J., and Luo, Z. (2017). Proteomic studies on fruit ripening and senescence. Crit. Rev. Plant Sci. 36, 116-127. doi: 10.1080/ 07352689.2017.1355173

Li, Y., Lu, Y. G., Li, L. L., Chu, Z. N., Zhang, H. Y., Li, H. X., et al. (2019). Impairment of hormone pathways results in a general disturbance of fruit primary metabolism in tomato. Food Chem. 274, 170-179. doi: 10.1016/ j.foodchem.2018.08.026

Liang, L., Zhang, B., Yin, X.-R., Xu, C.-J., Sun, C.-D., and Chen, K.-S. (2013). Differential expression of the CBF gene family during postharvest cold storage and subsequent shelf-life of peach fruit. Plant Mol. Biol. Rep. 31, 1358-1367. doi: $10.1007 / \mathrm{s} 11105-013-0600-5$

Licausi, F., Kosmacz, M., Weits, D. A., Giuntoli, B., Giorgi, F. M., Voesenek, L., et al. (2011). Oxygen sensing in plants is mediated by an N-end rule pathway for protein destabilization. Nature 479, 419-U177. doi: 10.1038/nature10536

Limami, A. M. (2014). "Adaptations of nitrogen metabolism to oxygen deprivation in plants," in Low Oxygen Stress in Plants. Eds. J. T. van Dongen and F. Licausi (Wien: Springer-Verlag), 209-221. doi: 10.1007/978-3-7091-1254-0_11

Lin, S. K., Wu, T., Lin, H. L., Zhang, Y. Q., Xu, S. C., Wang, J. G., et al. (2018). De novo analysis reveals transcriptomic responses in Eriobotrya japonica fruits during postharvest cold storage. Genes 9(12), 639. doi: 10.3390/ genes9120639

Liu, R. L., Wang, Y. Y., Qin, G. Z., and Tian, S. P. (2016). Molecular basis of 1methylcyclopropene regulating organic acid metabolism in apple fruit during storage. Postharv. Biol. Technol. 117, 57-63. doi: 10.1016/j.postharvbio.2016.02.001

Lombardo, V. A., Osorio, S., Borsani, J., Lauxmann, M. A., Bustamante, C. A., Budde, C. O., et al. (2011). Metabolic profiling during peach fruit development and ripening reveals the metabolic networks that underpin each developmental stage. Plant Physiol. 157, 1696-1710. doi: 10.1104/pp.111.186064

Lopez-Bucio, J., Nieto-Jacobo, M. F., Ramirez-Rodriguez, V., and Herrera-Estrella, L. (2000). Organic acid metabolism in plants: from adaptive physiology to transgenic varieties for cultivation in extreme soils. Plant Sci. 160, 1-13. doi: 10.1016/s01689452(00)00347-2

Lumpkin, C., Fellman, J. K., Rudell, D. R., and Mattheis, J. (2014). 'Scarlett Spur Red Delicious' apple volatile production accompanying physiological disorder development during low $\mathrm{pO}_{2}$ controlled atmosphere storage. J. Agric. Food Chem. 62, 1741-1754. doi: 10.1021/jf405267b

Mainardi, J. A., Purgatto, E., Junior, A. V., Bastos, W. A., Cordenunsi, B. R., Do Nascimento, J. R. O., et al. (2006). Effects of ethylene and 1-methylcyclopropene (1-MCP) on gene expression and activity profile of alpha-1,4-glucanphosphorylase during banana ripening. J. Agric. Food Chem. 54, 7294-7299. doi: 10.1021/jf061180k

Manganaris, G. A., Rasori, A., Bassi, D., Geuna., F., Ramina, A., Tonutti, P., et al. (2011). Comparative transcript profiling of apricot (Prunus armeniaca L.) fruit development and on-tree ripening. Tree Genet. Genomes 7, 609-616. doi: 10.1007/s11295-010-0360-4 
Marangoni, A. G., Palma, T., and Stanley, D. W. (1996). Membrane effects in postharvest physiology. Postharv. Biol. Technol. 7, 193-217. doi: 10.1016/09255214(95)00042-9

Martinez-Romero, D., Bailen, G., Serrano, M., Guillen, F., Valverde, J. M., Zapata, P., et al. (2007). Tools to maintain postharvest fruit and vegetable quality through the inhibition of ethylene action: a review. Crit. Rev. Food Sci. Nutr. 47, 543-560. doi: 10.1080/10408390600846390

Michaeli, S., and Fromm, H. (2015). Closing the loop on the GABA shunt in plants: are GABA metabolism and signaling entwined? Front. Plant Sci. 6, 419. doi: 10.3389/fpls.2015.00419

Minas, I. S., Forcada, C., Dangl, G. S., Gradziel, T. M., Dandekar, A. M., and Crisosto, C. H. (2015). Discovery of non-climacteric and suppressed climacteric bud sport mutations originating from a climacteric Japanese plum cultivar (Prunus salicina Lindl.). Front. In Plant Sci. 6, 316. doi: 10.3389/fpls.2015.00316

Moing, A. (2000). Sugar alcohols as carbohydrate reserves in some higher plants. Developments Crop Sci. 26, 337-358. doi: 10.1016/S0378-519X(00)80017-3

Mulas, M., Fadda, A., and Angioni, A. (2013). Effect of maturation and cold storage on the organic acid composition of myrtle fruits. J. Sci. Food Agric. 93, 37-44. doi: 10.1002/jsfa.5724

Mustroph, A., Zanetti, M. E., Jang, C. J. H., Holtan, H. E., Repetti, P. P., Galbraith, D. W., et al. (2009). Profiling translatomes of discrete cell populations resolves altered cellular priorities during hypoxia in Arabidopsis. Proc. Natl. Acad. Sci. U. S. A. 106, 18843-18848. doi: 10.1073/pnas.0906131106

Mustroph, A., Lee, S. C., Oosumi, T., Zanetti, M. E., Yang, H. J., Ma, K., et al. (2010). Cross-kingdom comparison of transcriptomic adjustments to lowoxygen stress highlights conserved and plant-specific responses. Plant Physiol. 152, 1484-1500. doi: 10.1104/pp.109.151845

Mustroph, A., Stock, J., Hess, N., Aldous, S., Dreilich, A., and Grimm, B. (2013). Characterization of the phosphofructokinase gene family in rice and its expression under oxygen deficiency stress. Front. Plant Sci. 4, 125. doi: 10.3389/fpls.2013.00125

Mustroph, A., Barding, G. A., Kaiser, K. A., Larive, C. K., and Bailey-Serres, J. (2014). Characterization of distinct root and shoot responses to low-oxygen stress in Arabidopsis with a focus on primary C- and N-metabolism. Plant Cell Environ. 37, 2366-2380. doi: 10.1111/pce.12282

Narsai, R., Rocha, M., Geigenberger, P., Whelan, J., and Van Dongen, J. T. (2011). Comparative analysis between plant species of transcriptional and metabolic responses to hypoxia. New Phytol. 190, 472-487. doi: 10.1111/j.14698137.2010.03589.x

Nascimento, J. R. O., Cordenunsi, B. R., and Lajolo, F. M. (1997). Partial purification and characterization of sucrose phosphate synthase from preclimacteric and climacteric bananas. J. Agric. Food Chem. 45, 1103-1107. doi: $10.1021 /$ jf960407g

Neuwald, D. A., Streif, J., and Kittemann, D. (2010). Fruit starch degradation patterns in apple cultivars on-tree and off-tree at different holding temperatures. Acta Hortic. 858, 263-266. doi: 10.17660/ActaHortic. 2010.858.39

Nguyen-Quoc, B., and Foyer, C. H. (2001). A role for 'futile cycles' involving invertase and sucrose synthase in sucrose metabolism of tomato fruit. J. Exp. Bot. 52, 881-889. doi: 10.1093/jexbot/52.358.881

Nilo-Poyanco, R., Vizoso, P., Sanhueza, D., Balic, I., Meneses, C., Orellana, A., et al. (2019). A Prunus persica genome-wide RNA-seq approach uncovers major differences in the transcriptome among chilling injury sensitive and non-sensitive varieties. Physiol. Plant 166, 772-793. doi: 10.1111/ppl.12831

Ohlrogge, J., and Browse, J. (1995). Lipid biosynthesis. Plant Cell 7, 957-970. doi: 10.1105/tpc.7.7.957

Oliveira, H. C., and Sodek, L. (2013). Effect of oxygen deficiency on nitrogen assimilation and amino acid metabolism of soybean root segments. Amino Acids 44, 743-755. doi: 10.1007/s00726-012-1399-3

Paul, V., Pandey, R., and Srivastava, G. C. (2012). The fading distinctions between classical patterns of ripening in climacteric and non-climacteric fruit and the ubiquity of ethylene-an overview. J. Food Sci. Technol. Mysore 49, 1-21. doi: 10.1007/s13197-011-0293-4

Pedreschi, R., Vanstreels, E., Carpentier, S., Hertog, M., Lammertyn, J., Robben, J., et al. (2007). Proteomic analysis of core breakdown disorder in Conference pears (Pyrus communis L.). Proteomics 7, 2083-2099. doi: 10.1002/pmic.200600723
Pedreschi, R., Hertog, M., Robben, J., Noben, J. P., and Nicolai, B. (2008). Physiological implications of controlled atmosphere storage of 'Conference' pears (Pyrus communis L.): a proteomic approach. Postharv. Biol. Technol. 50, 110-116. doi: 10.1016/j.postharvbio.2008.04.004

Pedreschi, R., Franck, C., Lammertyn, J., Erban, A., Kopka, J., Hertog, M., et al. (2009). Metabolic profiling of 'Conference' pears under low oxygen stress. Postharv. Biol. Technol. 51, 123-130. doi: 10.1016/j.postharvbio.2008.05.019

Planchet, E., Lothier, J., and A.M., L. (2017). "Hyopxic respiratory metabolism in plants: Reorchestration of nitrogen and carbon metabolisms," in Plant Respiration: Metabolic fluxes and Carbon Balance. Eds. G. Tcherkez and J. Ghashghaie (Cham: Springer), 209-226.

Pons, C., Mart, C., Forment, J., Crisosto, C. H., Dandekar, A. M., and Granell, A. (2014). A bulk segregant gene expression analysis of a peach population reveals components of the underlying mechanism of the fruit cold response. PloS One 9, e90706. doi: 10.1371/journal.pone.0090706

Pons, C., Mart, C., Forment, J., Crisosto, C. H., Dandekar, A. M., and Granell, A. (2016). A genetic genomics-expression approach reveals components of the molecular mechanisms beyond the cell wall that underlie peach fruit woolliness due to cold storage. Plant Mol. Biol. 92, 483-503. doi: 10.1007/s11103-0160526-Z

Prange, R. K., DeLong, J. M., Daniels-Lake, B. J., and Harrison, P. A. (2005). Innovation in controlled atmosphere technology. Stewart Postharv. Rev. 1, 1-11. doi: 10.2212/spr.2005.3.9

Re, M. D., Gonzalez, C., Sdrigotti, M. A., Sorrequieta, A., Valle, E. M., and Boggio, S. B. (2012). Ripening tomato fruit after chilling storage alters protein turnover. J. Sci. Food Agric. 92, 1490-1496. doi: 10.1002/jsfa.4732

Rocha, M., Licausi, F., Araujo, W. L., Nunes-Nesi, A., Sodek, L., Fernie, A. R., et al. (2010). Glycolysis and the tricarboxylic acid cycle are linked by alanine aminotransferase during hypoxia induced by waterlogging of Lotus japonicus. Plant Physiol. 152, 1501-1513. doi: 10.1104/pp.109.150045

Saltveit, M. E. (1999). Effect of ethylene on quality of fresh fruits and vegetables. Postharv. Biol. Technol. 15, 279-292. doi: 10.1016/s0925-5214(98)00091-x

Salzano, A. M., Renzone, G., Sobolev, A. P., Carbone, V., Petriccione, M., Capitani, D., et al. (2019). Unveiling kiwifruit metabolite and protein changes in the course of postharvest cold storage. Front. Plant Sci. 10, 71. doi: 10.3389/fpls.2019.00071

Saquet, A. A., and Streif, J. (2008). Fermentative metabolism in 'Jonagold' apples under controlled atmosphere storage. Eur. J. Hortic. Sci. 73, 43-46.

Saquet, A. A., Streif, J., and Bangerth, F. (2003). Energy metabolism and membrane lipid alterations in relation to brown heart development in 'Conference' pears during delayed controlled atmosphere storage. Postharv. Biol. Technol. 30, 123-132. doi: 10.1016/s0925-5214(03)00099-1

Saraiva, L. A., Castelan, F. P., Gomes, B. L., Purgatto, E., and Cordenunsi-Lysenko, B. R. (2018). Thap maeo bananas: fast ripening and full ethylene perception at low doses. Food Res. Int. 105, 384-392. doi: 10.1016/j.foodres.2017.11.007

Shang, H. T., Cao, S. F., Yang, Z. F., Cai, Y. T., and Zheng, Y. H. (2011). Effect of exogenous g-aminobutyric acid treatment on proline accumulation and chilling injury in peach fruit after long-term cold storage. J. Agric. Food Chem. 59, 1264-1268. doi: 10.1021/jf104424z

Sheng, L., Zhou, X., Liu, Z. Y., Wang, J. W., Zhou, Q., Wang, L., et al. (2016). Changed activities of enzymes crucial to membrane lipid metabolism accompany pericarp browning in 'Nanguo' pears during refrigeration and subsequent shelf life at room temperature. Postharv. Biol. Technol. 117, 1-8. doi: 10.1016/j.postharvbio.2016.01.015

Shi, Y., Jiang, L., Zhang, L., Kang, R. Y., and Yu, Z. F. (2014). Dynamic changes in proteins during apple (Malus $x$ domestica) fruit ripening and storage. Hort. Res. 1, 21. doi: 10.1038/hortres.2014.6

Shi, F., Zhou, X., Zhou, Q., Tan, Z., Yao, M. M., Wei, B. D., et al. (2018). Membrane lipid metabolism changes and aroma ester loss in low-temperature stored Nanguo pears. Food Chem. 245, 446-453. doi: 10.1016/ j.foodchem.2017.10.091

Shiga, T. M., Soares, C. A., Nascimento, J. R. O., Purgatto, E., Lajolo, F. M., and Cordenunsi, B. R. (2011). Ripening-associated changes in the amounts of starch and non-starch polysaccharides and their contributions to fruit softening in three banana cultivars. J. Sci. Food Agric. 91, 1511-1516. doi: 10.1002/jsfa.4342

Shingaki-Wells, R. N., Huang, S. B., Taylor, N. L., Carroll, A. J., Zhou, W. X., and Millar, A. H. (2011). Differential molecular responses of rice and wheat coleoptiles to anoxia reveal novel metabolic adaptations in amino acid 
metabolism for tissue tolerance. Plant Physiol. 156, 1706-1724. doi: 10.1104/ pp.111.175570

Sisler, E. C., and Serek, M. (2003). Compounds interacting with the ethylene receptor in plants. Plant Biol. 5, 473-480. doi: 10.1055/s-2003-44782

Storch, T. T., Finatto, T., Bruneau, M., Orsel-Baldwin, M., Renou, J. P., Rombaldi, C. V., et al. (2017). Contrasting transcriptional programs control postharvest development of apples (Malus $x$ domestica Borkh.) submitted to cold storage and ethylene blockage. J. Agric. Food Chem. 65, 7813-7826. doi: 10.1021/ acs.jafc.7b01425

Sweetlove, L. J., Beard, K. F. M., Nunes-Nesi, A., Fernie, A. R., and Ratcliffe, R. G. (2010). Not just a circle: flux modes in the plant TCA cycle. Trends Plant Sci. 15, 462-470. doi: 10.1016/j.tplants.2010.05.006

Sweetman, C., Deluc, L. G., Cramer, G. R., Ford, C. M., and Soole, K. L. (2009). Regulation of malate metabolism in grape berry and other developing fruits. Phytochemistry 70, 1329-1344. doi: 10.1016/j.phytochem.2009.08.006

Takayama, M., and Ezura, H. (2015). How and why does tomato accumulate a large amount of GABA in the fruit? Front. Plant Sci. 6, 612. doi: 10.3389/ fpls.2015.00612

Tao, D. B., Wang, J. W., Zhang, L., Jiang, Y. G., and Lv, M. (2019). 1-Methylcyclopropene alleviates peel browning of 'Nanguo' pears by regulating energy, antioxidant and lipid metabolisms after long term refrigeration. Sci. Hortic. 247, 254-263. doi: 10.1016/j.scienta.2018.12.025

Thammawong, M., and Arakawa, O. (2007). Starch degradation of detached apple fruit in relation to ripening and ethylene. J. Japanese Soc. Hortic. Sci. 76, 345350. doi: $10.2503 /$ jjshs. 76.345

Thammawong, M., and Arakawa, O. (2010). Starch to sugar conversion in "Tsugaru" apples under ethylene and 1-methylcyclopropene treatments. $J$. Agric. Sci. Technol. 12, 617-626.

Thompson, A., Prange, R. K., Bancroft, R., and Puttongsiri, T. (2018). Controlled Atmosphere Storage of Fruit and Vegetables (Wallingford, Oxon, UK; Cambridge, MA, USA: CABI).

Tonutti, P. (2015). The technical evolution of CA storage protocols and the advancements in elucidating the fruit responses to low oxygen stress. Acta Hortic. 1079, 53-60. doi: 10.17660/ActaHortic.2015.1079.4

Trobacher, C. P., Clark, S. M., Bozzo, G. G., Mullen, R. T., DeEll, J. R., and Shelp, B. J. (2013). Catabolism of GABA in apple fruit: subcellular localization and biochemical characterization of two $\gamma$-aminobutyrate transarninases. Postharv. Biol. Technol. 75, 106-113. doi: 10.1016/j.postharvbio.2012.08.005

Tucker, G., Yin, X. R., Zhang, A. D., Wang, M. M., Zhu, Q. G., Liu, X. F., et al. (2017). Ethylene and fruit softening. Food Qual. Saf. 1, 253-267. doi: 10.1093/ fqsafe/fyx 024

Valero, D., and Serrano, M. (2010). Postharvest biology and technology for preserving fruit quality (Boca Raton, Florida, USA: CRC Press).

Vandendriessche, T., Schafer, H., Verlinden, B. E., Humpfer, E., Hertog, M., and Nicolai, B. M. (2013). High-throughput NMR based metabolic profiling of Braeburn apple in relation to internal browning. Postharv. Biol. Technol. 80, 18-24. doi: 10.1016/j.postharvbio.2013.01.008

Walker, R. P., Battistelli, A., Moscatello, S., Tecsi, L., Leegood, R. C., and Famiani, F. (2015). Phosphoenolpyruvate carboxykinase and gluconeogenesis in grape pericarp. Plant Physiol. Biochem. 97, 62-69. doi: 10.1016/j.plaphy.2015.09.004

Wang, K., Shao, X. F., Gong, Y. F., Zhu, Y., Wang, H. F., Zhang, X. L., et al. (2013). The metabolism of soluble carbohydrates related to chilling injury in peach fruit exposed to cold stress. Postharv. Biol. Technol. 86, 53-61. doi: 10.1016/ j.postharvbio.2013.06.020

Wang, Y. S., Luo, Z. S., Mao, L. C., and Ying, T. J. (2016). Contribution of polyamines metabolism and GABA shunt to chilling tolerance induced by nitric oxide in cold-stored banana fruit. Food Chem. 197, 333-339. doi: 10.1016/j.foodchem.2015.10.118

Wang, L. B., Ma, M., Zhang, Y. R., Wu, Z. F., Guo, L., Luo, W. Q., et al. (2018). Characterization of the genes involved in malic acid metabolism from pear fruit and their expression profile after postharvest 1-MCP/ethrel treatment. J. Agric. Food Chem. 66, 8772-8782. doi: 10.1021/acs.jafc.8b02598

Wang, L., Shan, T. M., Xie, B., Ling, C., Shao, S., Jin, P., et al. (2019). Glycine betaine reduces chilling injury in peach fruit by enhancing phenolic and sugar metabolisms. Food Chem. 272, 530-538. doi: 10.1016/j.foodchem.2018.08.085

Wang, Y. J., Ji, S. J., Dai, H. Y., Kong, X. M., Hao, J., Wang, S. Y., et al. (2019). Changes in membrane lipid metabolism accompany pitting in blueberry during refrigeration and subsequent storage at room temperature. Front. Plant Sci. 10, 829. doi: 10.3389/fpls.2019.00829

Wang, X. M. (1999). The role of phospholipase D in signaling cascades. Plant Physiol. 120, 645-651. doi: 10.1104/pp.120.3.645

Watkins, C. B. (2006). The use of 1-methylcyclopropene (1-MCP) on fruits and vegetables. Biotech. Adv. 24, 389-409. doi: 10.1016/j.biotechadv.2006.01.005

Watkins, C. B. (2015). "Advances in the use of 1-MCP," in Advances in Postharvest Fruit and Vegetable Technology. Eds. R. B. H. Wills and J. Golding (Boca Raton, Florida, USA: CRC Press), 117-146.

Wills, R. B. H., and Golding, J. B. (2016). Postharvest: an introduction to the physiology and handling of fruit and vegetables (Wallingford, Oxon, UK; Cambridge, MA, USA: CABI).

Xiao, Y. Y., Kuang, J. F., Qi, X. N., Ye, Y. J., Wu, Z. X., Chen, J. Y., et al. (2018). A comprehensive investigation of starch degradation process and identification of a transcriptional activator MabHLH6 during banana fruit ripening. Plant Biotechnol. J. 16, 151-164. doi: 10.1111/pbi.12756

Xie, L. J., Chen, Q. F., Chen, M. X., Yu, L. J., Huang, L., Chen, L., et al. (2015). Unsaturation of very long chain ceramides protects plant from hypoxiainduced damages by modulating ethylene signaling in Arabidopsis. PloS Genet. 11, 3. doi: 10.1371/journal.pgen.1005143

Xu, F. X., Liu, S. Y., Liu, Y. F., Xu, J., Liu, T., and Dong, S. Z. (2019). Effectiveness of lysozyme coatings and 1-MCP treatments on storage and preservation of kiwifruit. Food Chem. 288, 201-207. doi: 10.1016/j.foodchem.2019.03.024

Yahia, E. M. (2009). Modified and controlled atmospheres for the storage, transportation, and packaging of horticultural commodities (Boca Raton: CRC Press).

Yan, H. L., Wu, F. W., Jiang, G. X., Xiao, L., Li, Z. W., Duan, X. W., et al. (2019). Genome-wide identification, characterization and expression analysis of NF-Y gene family in relation to fruit ripening in banana. Postharv. Biol. Technol. 151, 98-110. doi: 10.1016/j.postharvbio.2019.02.002

Yang, A. P., Cao, S. F., Yang, Z. F., Cai, Y. T., and Zheng, Y. H. (2011). gAminobutyric acid treatment reduces chilling injury and activates the defence response of peach fruit. Food Chem. 129, 1619-1622. doi: 10.1016/ j.foodchem.2011.06.018

Yun, Z., Jin, S., Ding, Y. D., Wang, Z., Gao, H. J., Pan, Z. Y., et al. (2012). Comparative transcriptomics and proteomics analysis of citrus fruit, to improve understanding of the effect of low temperature on maintaining fruit quality during lengthy post-harvest storage. J. Exp. Bot. 63, 2873-2893. doi: $10.1093 / \mathrm{jxb} / \mathrm{err} 390$

Zanella, A., and Sturz, S. (2015). Optimizing postharvest life of horticultural products by means of dynamic CA: fruit physiology controls atmosphere composition during storage. Acta Hortic. 1071, 59-68. doi: 10.17660/ ActaHortic.2015.1071.4

Zeng, Y., Wu, Y., Avigne, W. T., and Koch, K. E. (1999). Rapid repression of maize invertases by low oxygen. Invertase/sucrose synthase balance, sugar signaling potential, and seedling survival. Plant Physiol. 121, 599-608. doi: 10.1104/ pp.121.2.599

Zhang, C., Ding, Z., Xu, X., Wang, Q., Qin, G., and Tian, S. (2010). Crucial roles of membrane stability and its related proteins in the tolerance of peach fruit to chilling injury. Amino Acids 39, 181-194. doi: 10.1007/s00726-009-0397-6

Zhang, L., Jiang, L., Shi, Y., Luo, H. B., Rang, R. Y., and Yu, Z. F. (2012). Postharvest 1-methylcyclopropene and ethephon treatments differently modify protein profiles of peach fruit during ripening. Food Res. Int. 48, 609-619. doi: 10.1016/j.foodres.2012.05.022

Zhang, L. P., Shen, Y. X., Bu, Q. Z., and Ji, S. J. (2014). Effects of 1methylcyclopropene on the metabolic pathways of aroma-related compounds in Nanguo pear. J. Food Process. Preserv. 38, 1749-1758. doi: $10.1111 /$ jfpp. 12138

Zhang, A. D., Wang, W. Q., Tong, Y., Li, M. J., Grierson, D., Ferguson, I., et al. (2018). Transcriptome analysis identifies a zinc finger protein regulating starch degradation in kiwifruit. Plant Physiol. 178, 850-863. doi: 10.1104/pp.18.00427

Zhao, H. D., Jiao, W. X., Cui, K. B., Fan, X. G., Shu, C., Zhang, W. L., et al. (2019). Near-freezing temperature storage enhances chilling tolerance in nectarine fruit through its regulation of soluble sugars and energy metabolism. Food Chem. 289, 426-435. doi: 10.1016/j.foodchem.2019.03.088

Zhao, X. D., Yuan, X. Y., Chen, S., Fu, D. Q., and Jiang, C. Z. (2019). Metabolomic and transcriptomic analyses reveal that a MADS-Box transcription factor 
TDR4 regulates tomato fruit quality. Front. Plant Sci. 10, 10. doi: 10.3389/ fpls.2019.00792

Zhou, Y. C., Pan, X. P., Qu, H. X., and Underhill, S. J. R. (2014). Low temperature alters plasma membrane lipid composition and ATPase activity of pineapple fruit during blackheart development. J. Bioenerget. Biomembranes 46, 59-69. doi: 10.1007/s10863-013-9538-4

Zhou, D. D., Chen, S. X., Xu, R., Tu, S. C., and Tu, K. (2019). Interactions among chilling tolerance, sucrose degradation and organic acid metabolism in UV-Cirradiated peach fruit during postharvest cold storage. Acta Physiol. Plant 41 (6), 79. doi: 10.1007/s11738-019-2871-4

Zhu, Z., Liu, R., Li, B., and Tian, S. (2013). Characterisation of genes encoding key enzymes involved in sugar metabolism of apple fruit in controlled atmosphere storage. Food Chem. 141, 3323-3328. doi: 10.1016/j.foodchem.2013.06.025

Zhu, Q. G., Gong, Z. Y., Wang, M. M., Li, X., Grierson, D., Yin, X. R., et al. (2018). A transcription factor network responsive to high $\mathrm{CO}_{2}$ /hypoxia is involved in deastringency in persimmon fruit. J. Exp. Bot. 69, 2061-2070. doi: 10.1093/jxb/ery028

Zhu, Q. G., Gong, Z. Y., Huang, J., Grierson, D., Chen, K. S., and Yi, X. R. (2019). High- $\mathrm{CO}_{2}$ /hypoxia-responsive transcription factors DkERF24 and DkWRKY1 interact and activate DkPDC2 promoter. Plant Physiol. 108, 621-633. doi: 10.1104/pp.18.01552

Ziliotto, F., Begheldo, M., Rasori, A., Bonghi, C., and Tonutti, P. (2008). Transcriptome profiling of ripening nectarine (Prunus persica L. Batsch) fruit treated with 1-MCP. J. Exp. Bot. 59, 2781-2791. doi: 10.1093/jxb/ ern136

Conflict of Interest: The authors declare that the research was conducted in the absence of any commercial or financial relationships that could be construed as a potential conflict of interest.

Copyright $\odot 2020$ Brizzolara, Manganaris, Fotopoulos, Watkins and Tonutti. This is an open-access article distributed under the terms of the Creative Commons Attribution License (CC BY). The use, distribution or reproduction in other forums is permitted, provided the original author(s) and the copyright owner(s) are credited and that the original publication in this journal is cited, in accordance with accepted academic practice. No use, distribution or reproduction is permitted which does not comply with these terms. 